\title{
Multi-instrument gravity-wave measurements over Tierra del Fuego and the Drake Passage - Part 1: Potential energies and vertical wavelengths from AIRS, COSMIC, HIRDLS, MLS-Aura, SAAMER, SABER and radiosondes
}

\author{
Corwin J. Wright, Neil P. Hindley, Andrew C. Moss, and Nicholas J. Mitchell \\ Centre for Space, Atmospheric and Oceanic Science, University of Bath, Claverton Down, Bath BA2 7AY, UK \\ Correspondence to: Corwin J. Wright (corwin.wright@trinity.oxon.org)
}

Received: 4 June 2015 - Published in Atmos. Meas. Tech. Discuss.: 6 July 2015

Revised: 4 February 2016 - Accepted: 9 February 2016 - Published: 4 March 2016

\begin{abstract}
Gravity waves in the terrestrial atmosphere are a vital geophysical process, acting to transport energy and momentum on a wide range of scales and to couple the various atmospheric layers. Despite the importance of these waves, the many studies to date have often exhibited very dissimilar results, and it remains unclear whether these differences are primarily instrumental or methodological. Here, we address this problem by comparing observations made by a diverse range of the most widely used gravity-wave-resolving instruments in a common geographic region around the southern Andes and Drake Passage, an area known to exhibit strong wave activity. Specifically, we use data from three limbsounding radiometers (Microwave Limb Sounder, MLSAura; HIgh Resolution Dynamics Limb Sounder, HIRDLS; Sounding of the Atmosphere using Broadband Emission Radiometry, SABER), the Constellation Observing System for Meteorology, Ionosphere and Climate (COSMIC) GPS-RO constellation, a ground-based meteor radar, the Advanced Infrared Sounder (AIRS) infrared nadir sounder and radiosondes to examine the gravity wave potential energy (GWPE) and vertical wavelengths $\left(\lambda_{z}\right)$ of individual gravity-wave packets from the lower troposphere to the edge of the lower thermosphere $(\sim 100 \mathrm{~km})$. Our results show important similarities and differences. Limb sounder measurements show high intercorrelation, typically $>0.80$ between any instrument pair. Meteor radar observations agree in form with the limb sounders, despite vast technical differences. AIRS and radiosonde observations tend to be uncorrelated or anticorrelated with the other data sets, suggesting very different be-
\end{abstract}

haviour of the wave field in the different spectral regimes accessed by each instrument. Evidence of wave dissipation is seen, and varies strongly with season. Observed GWPE for individual wave packets exhibits a log-normal distribution, with short-timescale intermittency dominating over a wellrepeated monthly-median seasonal cycle. GWPE and $\lambda_{z}$ exhibit strong correlations with the stratospheric winds, but not with local surface winds. Our results provide guidance for interpretation and intercomparison of such data sets in their full context.

\section{Introduction}

The last 2 decades have been a golden age for the measurement of gravity waves in the terrestrial atmosphere. These waves, which are a key driving mechanism for atmospheric processes at all scales and altitudes, are an integral part of our understanding of a vast range of atmospheric processes, including cloud formation, the quasi-biennial and semi-annual oscillations in the stratosphere, stratospheric jets, the Brewer-Dobson circulation, and the maintenance of the mean upper-atmospheric structure.

The development of new instruments, such as highvertical-resolution limb-sounding satellites (Wu and Eckermann, 2008; Gille et al., 2008) and long-duration tracer balloons (Hertzog et al., 2008, 2012), has led to extensive new data sets which can be used to study the distribution and behaviour of these waves. In parallel with these new observa- 
tions, advanced methods for extracting new information from more traditional atmospheric measurement techniques have been developed, from in situ radiosondes (Vincent and Allen, 1996; Guest et al., 2000) in the troposphere to wind measurements inferred from meteor trails in the upper mesosphere (Hocking, 2005; Davies et al., 2015). This avalanche of information has allowed novel studies which have investigated wave processes from pole-to-pole and from the surface to the thermosphere.

These advances have allowed us to begin to study in detail the extremely broad range of dynamical and chemical processes affected by gravity waves throughout the atmosphere (e.g. Fritts and Alexander, 2003; Alexander et al., 2010, and references therein). However, the resulting knowledge, while broad, is often shallow. A critical limitation is that no existing observational technique combines the global scale and reach needed with the spectral and temporal coverage necessary to study the full spectrum and geographic distribution of gravity waves (Alexander, 1998; Preusse et al., 2008; Alexander et al., 2010), and there is no proposed technique that will have that capability. This limitation is important because the variability of the wave spectrum, and consequently the dynamics the waves induce and affect, can vary substantially depending on the spectral properties of the wave.

Accordingly, the focus of observational gravity-wave research must now at least partially shift to understanding and interpreting our measurements in their complete multi-data set context, rather than as individual spotlights on particular parts of the wave spectrum. The need for such synergistic instrument measurements has been highlighted by, for example, Preusse et al. (2000) and Wu et al. (2006).

Such work is inherently technically challenging due to the very different observational biases of the instruments and methods used, and has thus lagged behind the collection and analysis of each individual data set. However, this work is vital if our understanding of wave-driven phenomena in the atmosphere is to reach the level of understanding at which it can be directly implemented in the next generation of weather and climate models (Alexander et al., 2010).

The difficulty of such comparisons has been highlighted recently by Geller et al. (2013), who analysed and compared gravity-wave measurements from satellites, balloons and leading climate models. Discrepancies were seen between the observational and model data sets, but dissimilarities were also seen between the different observational data sets. While this difficulty has been known for some time, (e.g. Alexander, 1998), the Geller et al. (2013) study highlighted these differences, with order-of-magnitude differences in wave momentum flux between data sets not atypical, even between identical data sets analysed using different methods.

The aim of the current study is to address these problems in several ways.

Firstly, we include additional observational techniques beyond those used by Geller et al. (2013), specifically nadir-sounding measurements from AIRS, additional limbsounding measurements from the Microwave Limb Sounder, MLS-Aura, and upper mesopheric measurements from meteor radar.

Secondly, we analyse each data set using methods as similar as possible to each other. This, for example, may elucidate whether the known differences between HIRDLS and Sounding of the Atmosphere using Broadband Emission Radiometry (SABER) measurements of gravity wave potential energies arise due to observational constraints or to analytical choices. This was done for momentum fluxes observed by HIRDLS and SABER by Geller et al. (2013); here, we extend it to additional instruments and to potential energies.

Thirdly, we extend the height range covered significantly in the vertical, extending from near-surface altitudes to the upper mesosphere.

We focus our work geographically on the region around Tierra del Fuego $\left(54^{\circ} \mathrm{S}, 68^{\circ} \mathrm{W}\right)$. This choice is not arbitrary: this region lies between the southern Andes and their continuation in the Antarctic Peninsula, arguably the two most intense sources of orographic gravity waves in the world, and allows us to combine a range of satellite instruments (AIRS, COSMIC, HIRDLS, MLS-Aura and SABER) with measurements obtained from the Southern Argentina Agile Meteor Radar (SAAMER) meteor radar located on Tierra del Fuego and radiosondes launched from the nearby Mt Pleasant highresolution radiosonde station. The methods and techniques used are in principle extensible to any geographic location. For reasons of space, we do not study model output.

We investigate the observed distribution of gravity wave potential energy per unit mass (GWPE) and gravity wave vertical wavelengths $\left(\lambda_{z}\right)$ over a $10^{\circ}$ latitude by $20^{\circ}$ longitude box centred on Tierra del Fuego $\left(54^{\circ} \mathrm{S} 68^{\circ} \mathrm{W}\right)$ for the satellite and radiosonde data sets, and the gravity-wave-induced wind variance for the SAAMER radar. To simplify the text, we use the term GWPE hereafter to describe both satellitederived GWPE and radar variance unless otherwise specified; it should be clearly noted, however, that the radar variance is more closely analogous to gravity wave kinetic energy (GWKE) (e.g Balsley and Garello, 1985; Geller and Gong, 2010), and this substitution is made purely for textual reasons.

A companion study (Part 2) will use the same data sets and geographic region to investigate gravity wave momentum fluxes (GWMFs) and horizontal wavelengths $\left(\lambda_{h}\right)$, and will investigate the effects of spectrally subsetting individual data sets to more closely correspond to each other.

The aim of the combined work is to provide a quantitative understanding of the key differences induced by the observational filters of these data sets in this region. The work thus provides guidance for the future intercomparison of observations of gravity waves made using these various techniques.

Section 2 describes the data sets we use in this study. Sections 3, 4 and 5 then describe the geographic, temporal, altitudinal and spectral coverage of each data set and the meth- 
ods we use to obtain estimates of GWPE and $\lambda_{z}$. We then discuss GWPE measurements in Sect. 6 and vertical wavelengths in Sect. 7. Finally, we draw conclusions in Sect. 8.

\section{Instruments and data sets}

\subsection{AIRS}

The Advanced Infrared Sounder (AIRS) is an infrared nadirsounding instrument on NASA's Aqua satellite, launched on the 4 May 2002 and with continuous data availability since shortly after that date (Aumann et al., 2003). Part of NASA's A-Train afternoon satellite constellation, Aqua flies in a 98 min sun-synchronous polar orbit, with an ascendingnode equator-crossing local solar time of 13:30. AIRS has 2378 spectral channels, which provide a continuous swath of radiance measurements with an average cross-track footprint width of $20 \mathrm{~km}$, varying from $13.5 \mathrm{~km}$ at the centre of the instrument track to $40 \mathrm{~km}$ at the edges across 90 parallel tracks. Data are processed in "granules" corresponding to $6 \mathrm{~min}$ of along-track data collection, with 135 rows of data in each granule (Olsen et al., 2007).

AIRS has been used to study atmospheric gravity waves in a range of recent studies (e.g. Alexander and Barnet, 2007; Alexander et al., 2009a; Hoffmann et al., 2014; Eckermann and Wu, 2012; Niranjan Kumar et al., 2012; Alexander and Grimsdell, 2013; Gong et al., 2015). We use AIRS Level 1 (version 5) radiance data; these data are available at considerably higher horizontal resolution than the AIRS Level 2 temperature product (Hoffmann and Alexander, 2009) and are consequently more useful for studying small-scale phenomena such as gravity waves. These data also preserve wave features in the vertical, which the methods used to optimise the standard AIRS Level 2 product will suppress (Alexander and Barnet, 2007). We use perturbations to measured radiance values to compute wave properties in the altitude range $\sim 16$ to $\sim 42 \mathrm{~km}$, using the channel selections of Gong et al. (2012) (listed in their Appendix A). These channels are centred at the 2, 2.5, 3, 4, 7, 10, 20, 30, 40, 60, 80 and $100 \mathrm{hPa}$ pressure levels, and their weighting functions are illustrated in Fig. 1a, which is discussed in greater detail below.

\subsection{COSMIC}

The Constellation Observing System for Meteorology, Ionosphere and Climate (COSMIC) is a joint US/Taiwanese mission based on a constellation of six identical microsatellites at an orbital altitude of $800 \mathrm{~km}$. Each satellite intercepts GPS signals transmitted through the atmosphere. The phase delay in these signals allows the bending angle of the transmission path through the atmosphere to be computed. These angles can then be analysed to produce profiles of temperature from the troposphere to a best-case altitude of around $60 \mathrm{~km}$ altitude, but with many profiles dropping out before reaching this level (Anthes et al., 2008; Barnett et al., 2008) ${ }^{1}$. Ionospheric noise begins to affect the signal above around $38 \mathrm{~km}$ (Tsuda et al., 2011), increasing in significance with height. We use the "dry" 2013 reprocessed version of the COSMIC Level 2 product.

COSMIC measurements are pseudo-randomly distributed across the globe due to the requirement for an optical path between a GPS and a COSMIC satellite and the differing orbits of the two constellations. Vertical resolution estimates, based on the size of the signal Fresnel zone in typical atmospheric conditions, range from $\sim 1.4 \mathrm{~km}$ in the stratosphere (Kursinski et al., 1997) to $\sim 100 \mathrm{~m}$ in the lower troposphere, with a precision of $\sim 0.5 \mathrm{~K}$ (Anthes et al., 2008; Tsuda et al., 2011). These measurements, together with those of the similar previous CHAMP mission, have been used for a vast range of gravity-wave-related studies, including for example Hei et al. (2008); Alexander et al. (2008b, 2009b); Wang and Alexander (2009); McDonald et al. (2010); Tsuda et al. (2011); McDonald (2012); Faber et al. (2013); John and Kumar (2013); Šácha et al. (2014) and Hindley et al. (2015).

Data are available from mid-2006 onwards, with around 1000-1500 profiles per day, declining slightly over the mission due to aging and loss of the satellites. These profiles are typically too widely separated in space and/or time to provide a useful estimate of GWMFs, with the exception of a period of $\sim 11$ months during the deployment phase of the mission when the satellites flew closely together (Barnett et al., 2008; Faber et al., 2013; Hindley et al., 2015). Consequently, GWMF estimates (Part 2) are only presented from this period, but estimates of other properties are shown for the duration of the mission.

\subsection{HIRDLS}

The HIgh Resolution Dynamics Limb Sounder (HIRDLS) is a 21-channel limb-scanning filter radiometer on NASA's Aura satellite (Gille et al., 2003; Schoeberl et al., 2006). Aura is also part of NASA's A-Train, with an ascendingnode equator-crossing time a few minutes after Aqua. Designed to measure high-vertical-resolution atmospheric radiance profiles, one particularly productive area of research has been the detection and analysis of gravity waves (GWs) (e.g. Alexander et al., 2008a; Hoffmann and Alexander, 2009; Wang and Alexander, 2009; Wright et al., 2010; Yan et al., 2010; France et al., 2012; Ern and Preusse, 2012; Wright and Gille, 2013). This is due to the close along-track profile spacing used for the majority of the mission, necessitated by an optical blockage discovered shortly after launch (Gille et al., 2008).

The blockage leads to observations from HIRDLS being obtained at a large angle to the rear line-of-sight of the instru-

\footnotetext{
${ }^{1}$ Throughout this study, we refer collectively to "limb sounders", which we define as COSMIC, HIRDLS, MLS-Aura and SABER. These instruments have very similar observational characteristics see e.g. Sect. 5.
} 

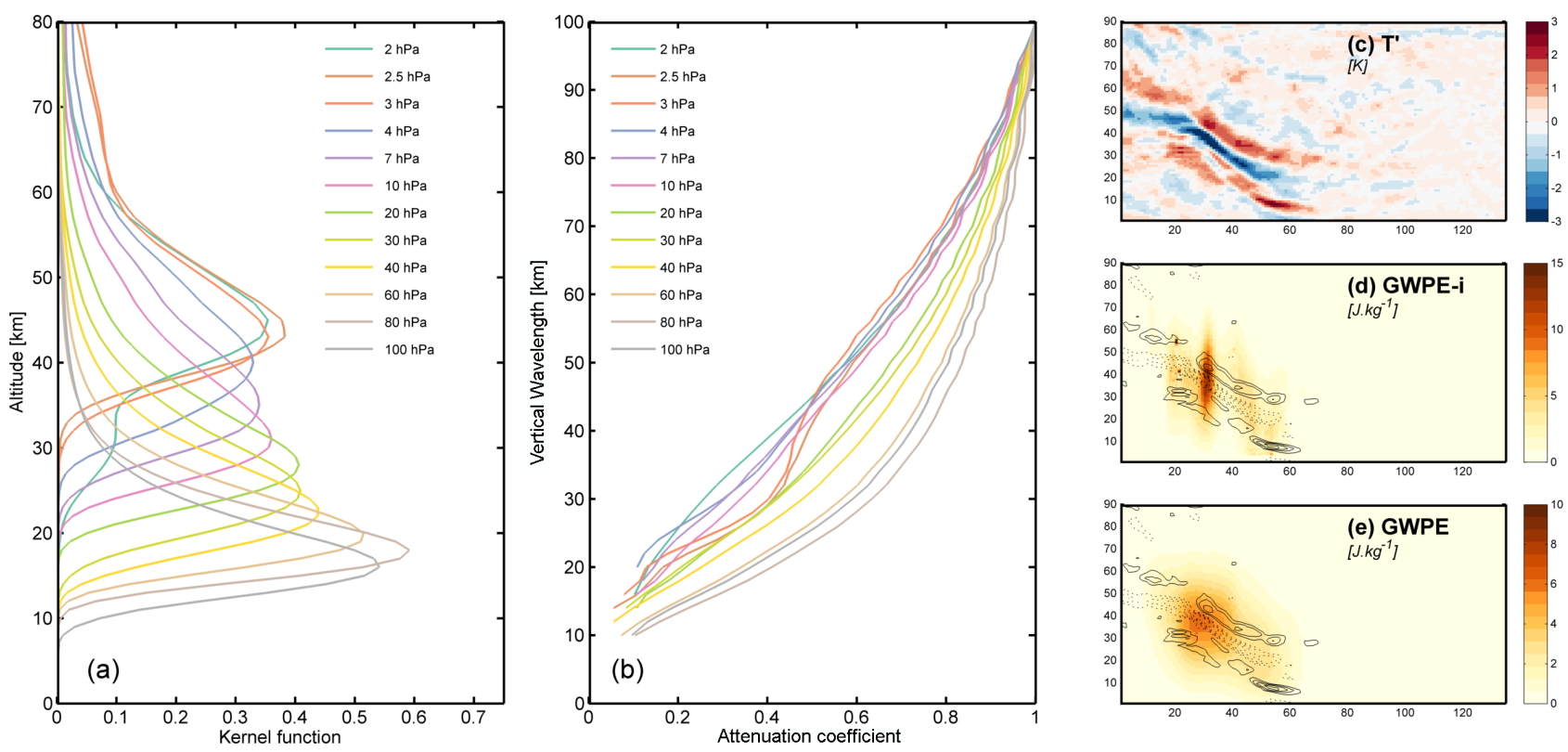

Figure 1. (a) Kernel ("weighting") functions of the AIRS channels used in our analysis, each plotted against height; (b) attenuation coefficients computed for a theoretical wave of amplitude unity for each channel, plotted against the vertical wavelength of the theoretical wave; (c) temperature perturbation granule observed by AIRS on 6 September 2003; (d) interim GWPE values computed from this measurement granule, with temperature perturbations from panel (c) overplotted for reference; (e) as (d), but smoothed with a 10-pixel disc smoother to approximate averaging over the full cycle of the wave.

ment, with measurements following a small circle $47^{\circ}$ offset from the orbital great circle, and thus not spatially co-located with other A-Train measurements. Around 5500 vertical profiles per day were collected globally between the commencement of scientific operations in January 2005 and the failure of the optical chopper in early 2008. These profiles are typically spaced approximately $70-120 \mathrm{~km}$ apart.

V007 of the HIRDLS data set provides vertical temperature profiles from the tropopause to $\sim 80 \mathrm{~km}$ in altitude as a function of pressure, allowing us to produce useful gravitywave analyses at these higher altitudes. Measurements have a precision $\sim 0.5 \mathrm{~K}$ throughout the stratosphere, decreasing smoothly to $\sim 1 \mathrm{~K}$ at the stratopause and $3 \mathrm{~K}$ or more above this, depending on latitude and season (Khosravi et al., 2009; Gille et al., 2013; Wright et al., 2015). Vertical resolution is $\sim 1 \mathrm{~km}$ in the stratosphere, rising smoothly between $\sim 60$ and $\sim 70$ to $\sim 2 \mathrm{~km}$.

\subsection{MLS-Aura}

The Microwave Limb Sounder is a limb-sounding instrument on NASA's Aura satellite. Based upon the heritage of the previous MLS, which flew aboard the UARS satellite in the early 1990s, MLS-Aura measures microwave emissions from the atmosphere in five spectral bands, allowing the observation of a range of physical quantities and chemical species (Schoeberl et al., 2006; Waters et al., 2006). In particular, atmospheric temperature and pressure are measured by the satellite, in the 118 and $239 \mathrm{GHz}$ bands. Measurements from
MLS-Aura started 15 days after the launch of Aura in mid2004, and continue to date.

We use version 3.3/3.4 (hereafter simply v3.3) of the MLS-Aura Level 2 product (Livesey et al., 2013). Although not the most recent version of the retrieval (which would be $\mathrm{v} 4.2$ ), this is the newest product which consistently covers the entire period under investigation at time of writing. Providing quality flags in the data set are used appropriately, differences in the temperature product between versions 4.2 and 3.3 should be small (Livesey et al., 2015).

MLS-Aura v3.3 temperature products cover the range $261-0.001 \mathrm{hPa}(\sim 10-100 \mathrm{~km})$. Resolution varies with height from 3.6 to $6 \mathrm{~km}$, and the minimum detectable vertical wavelength (defined as twice the vertical resolution) is illustrated in Fig. 6. Along-track resolution is $\sim 170 \mathrm{~km}$ from 261 to $0.1 \mathrm{hPa}$, degrading to $220 \mathrm{~km}$ at $0.001 \mathrm{hPa}$, with precision degrading from $0.6 \mathrm{~K}$ in the lower stratosphere to $2.5 \mathrm{~K}$ in the mesosphere (Livesey et al., 2013).

Due to its comparatively limited vertical resolution relative to other limb sounders, MLS-Aura is less often used to study gravity waves then some other data sets. There are some examples however, including Niranjan Kumar et al. (2012), using wavelet methods similar to ours (described below), Wu and Eckermann (2008), who used saturated variances rather than retrieved temperatures to allow access to smaller-vertical-wavelength features than are available with the methods used here, and Wright et al. (2016), who com- 

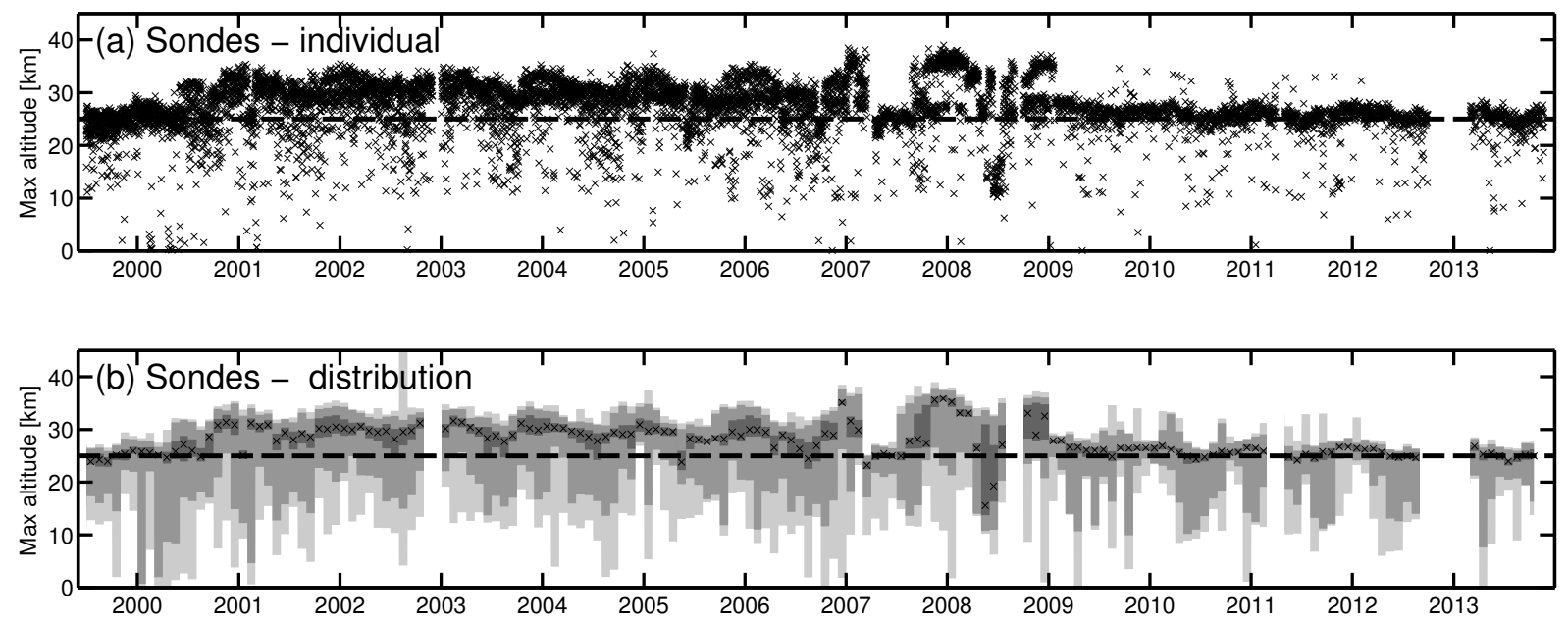

Figure 2. Maximum heights reached by radiosondes. Panel (a) shows a cross for each individual sonde. In (b) each column shows the distribution of maximum heights for the corresponding month, with colours indicating (in order of increasing saturation) the full range, 5th-95th percentile, and 32nd to 68th percentiles of maximum heights reached by that data set in that month. Crosses indicate the monthly median. One sonde extends above the figure axis (August 2003); this balloon reported a maximum altitude of $\sim 60 \mathrm{~km}$. Horizontal dashed lines indicate the required minimum height for a measurement to be included in our analysis.

bined MLS data with co-located AIRS data to measure GWMFs in three dimensions.

\subsection{SAAMER meteor radar}

The Southern Argentina Agile Meteor Radar (SAAMER) is a meteor radar system installed at Rio Grande on Tierra del Fuego $\left(53.8^{\circ} \mathrm{S}, 67.8^{\circ} \mathrm{W}\right)$ with a peak power of $60 \mathrm{~kW}$. Operating since May 2008, SAAMER measures the ionisation trails generated in the $70-110 \mathrm{~km}$ altitude range by $\sim 12000$ meteors per day (Fritts et al., 2010). The radar scatter from these ionisation trails can be used to infer the speed and direction of the local wind field, including the small perturbations to this field induced by gravity waves. SAAMER operates at significantly higher power levels than standard meteor radars, with a set-up designed to optimise the detection of off-zenith meteor trails, and is thus more sensitive to gravity-wave effects (Fritts et al., 2010).

The detected meteor trails are Gaussian-distributed about an altitude of $\sim 90 \mathrm{~km}$, and in practice, too few meteors are detected at heights below $\sim 80 \mathrm{~km}$ or above $\sim 100 \mathrm{~km}$ for gravity-wave analyses to be carried out.

\subsection{SABER}

A 10-channel limb-sounding infrared radiometer, SABER provides $\sim 2200$ profiles globally per day, with a vertical resolution of approximately $2 \mathrm{~km}$ and an along-track profile spacing alternating between 200 and $550 \mathrm{~km}$. Kinetic temperature profiles cover the $15-120 \mathrm{~km}$ altitude range, with a precision of $\sim 0.8 \mathrm{~K}$ (Wrasse et al., 2008; Remsberg et al., 2008). An LTE (local thermodynamic equilibrium)-assuming retrieval at low altitudes provides the lower boundary con- ditions for a non-LTE retrieval above $40 \mathrm{~km}$ (Mertens et al., 2009). Coverage shifts north and south every 60 days to cover the poles alternately. Accordingly, the majority of our analysis region is only fully covered for 60 in every 120 days; otherwise, measurements terminate slightly north of the site at $50^{\circ} \mathrm{S}$. Section 3.5 below investigates the effect of this varying cycle further. We use v2.0 data, which are available from 2002 onwards. SABER has also been used for a vast range of gravity-wave studies, e.g. Krebsbach and Preusse (2007); Preusse et al. (2009); Schroeder et al. (2009); John and Kumar (2012); Zhang et al. (2012); Ern et al. (2011) and Ern et al. (2014).

\subsection{Radiosondes}

We analyse data from the UK Met Office's Mt Pleasant radiosonde ${ }^{2}$ station, located on the Falkland Islands at $58.4^{\circ} \mathrm{W}$, $51.8^{\circ} \mathrm{S}$ (Met Office, 2015). This is geographically located near the easternmost edge of our analysis region. The Mt Pleasant station provides a 15-year record (1999-date) of high-resolution radiosondes, typically launched twice daily (11:00 and 23:00 UTC) with a $2 \mathrm{~s}$ temporal resolution during their ascent to altitudes between 20 and $40 \mathrm{~km}$; Fig. 2, discussed in more detail below, shows the actual maximum heights reached by each balloon we analyse.

Vaisala RS-80-H radiosondes were used until 2005, after which launches switched to Vaisala RS-92 radiosondes; Smout et al. (2005) investigated this change and concluded that data quality remained consistent across this transition.

\footnotetext{
${ }^{2}$ We use the terms "radiosonde" and "sonde" interchangeably throughout this study; in all cases, we refer to radiosondes specifically and no other type of sonde instrument.
} 

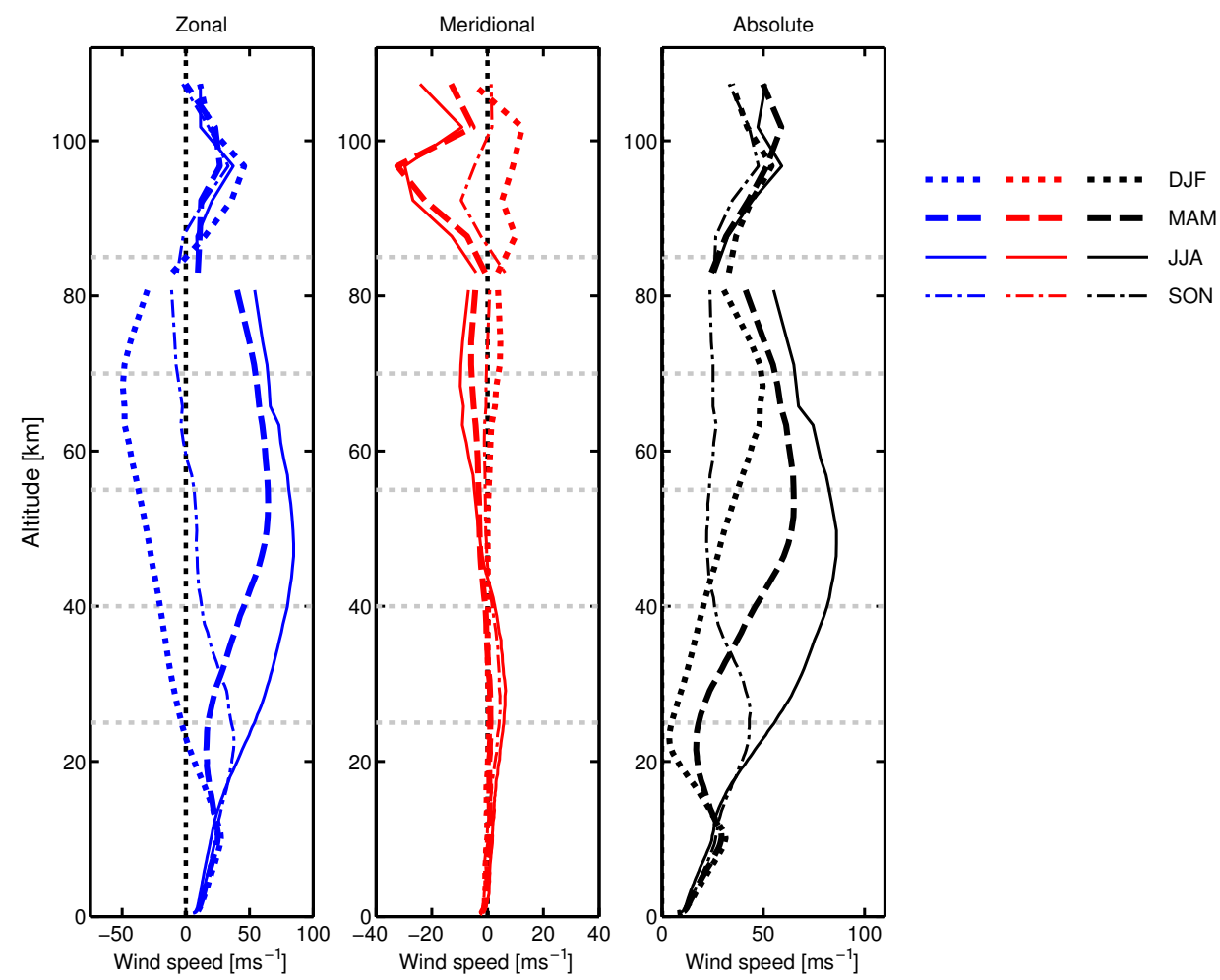

Figure 3. Zonal (left), meridional (centre) and absolute (right) seasonal-median winds derived from $(z<80 \mathrm{~km})$ ECMWF operational analyses for 2002-2012 $(z>80 \mathrm{~km})$ SAAMER observations for 2006-2012.

Following a change to more lightweight balloons in 2008 the typical peak altitude of the balloons was reduced (see Fig. 2). The data used here are the geometric altitudes, atmospheric temperatures and (in Part 2) wind speeds returned by the sondes.

High-resolution radiosondes are another hardy perennial of gravity-wave research, with a vast range of studies in the recent past. The Falklands radiosonde data set has been recently studied for gravity-wave effects by Moffat-Griffin et al. (2013).

\subsection{Wind}

To interpret our results, we make use of complementary wind information. We use ECMWF operational analyses (ECMWF, 2015) up to $80 \mathrm{~km}$ and SAAMER observations above $80 \mathrm{~km}$. These data are shown in Figs. 3 (seasonal medians against height) and 4 (time series at five specific altitude levels of interest). Values presented in Fig. 4 are daily medians over the region of interest, smoothed 14 days (ECMWF) and 31 days (SAAMER). The vertical dotted line on panels $(\mathrm{g})-(\mathrm{j})$ indicates the change to the number of levels in the ECMWF model from 60 to 91; before this date, the model did not extend above $0.1 \mathrm{hPa}(\sim 60 \mathrm{~km})$ altitude.

There is a significant discontinuity where the two data sets join; this may be due to methodological limitations in the meteor radar wind calculation method, limited assimilative observations contributing to ECMWF analyses at higher altitudes, or some combination of these effects. Detailed investigation of this effect is beyond the scope of this study. Although absolute values differ, the ordering of seasonal medians across the discontinuity in Fig. 3 usually remains constant, and thus the discrepancy may only be one of magnitude rather than direction.

\section{Data availability and geographic coverage}

The data availability and geographic coverage of our data sets differ greatly. Figures 5 and 6 illustrate the coverage available to each of our data sets, displayed in terms of geographic (Fig. 5a and 5b), altitudinal (Fig. 6a) and temporal (Fig. 6bh) coverage. Note that the colours and symbols associated with each instrument here are used for all subsequent figures in this study, in order to provide a visual key to the data being considered in each case.

\subsection{Geographic coverage}

Figure 5a shows the four limb-sounding data sets, i.e. COSMIC (orange), HIRDLS (red), MLS-Aura (mustard) and SABER (purple), all for a typical day (1 January 2006 for HIRDLS, MLS-Aura and SABER, 1 July 2008 for COS- 

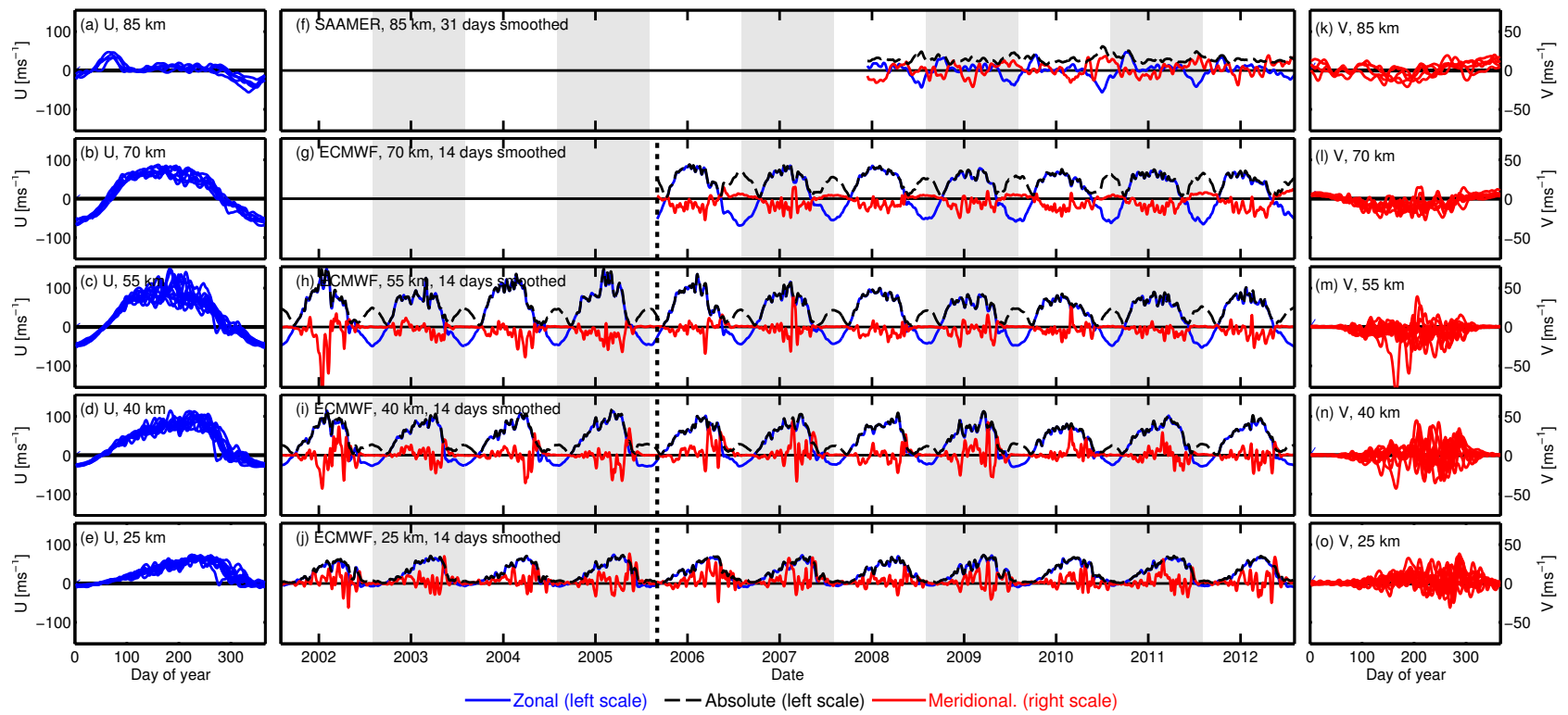

Figure 4. Zonal and meridional winds (left and right columns) computed from ECMWF operational analyses (25-70 km) and SAAMER observations $(85 \mathrm{~km})$. Time series of meridional (red), zonal (blue) and absolute (black dotted) wind (centre column). Note that there is a difference between left (zonal, absolute) and right (meridional) scales.

(a) COSMIC, HIRDLS, MLS and SABER

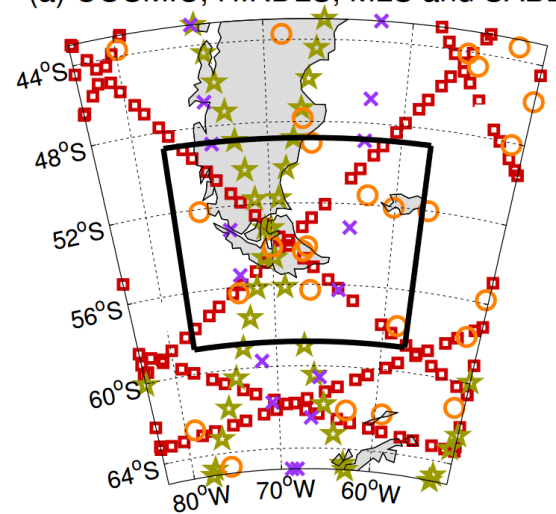

(b) AIRS, SAAMER and sondes

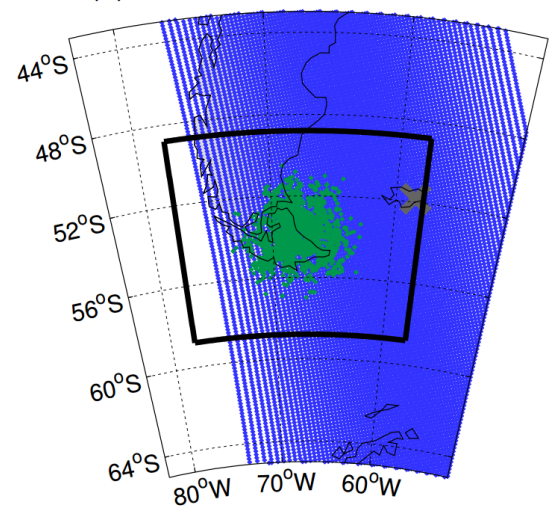

Figure 5. Panels (a) and (b) show geographic footprints of the data sets examined for a typical day (except AIRS: single descending-node pass only). The black box outlines the region averaged over for our analyses.

MIC). The black box indicates the region over which our results are averaged. HIRDLS, MLS-Aura and SABER precess geographically westwards every day systematically due to their consistent low-Earth orbit and the rotation of the Earth beneath them, whilst COSMIC profiles are pseudo-randomly distributed each day.

Figure 5b shows geographic footprints for AIRS (descending-node pass on 6 November 2002, blue, partially hidden by SAAMER coverage) and SAAMER (1 January 2010, green). The sonde launching station at Mt Pleasant is also indicated on this panel (grey cross). As with HIRDLS, MLS-Aura and SABER, the AIRS scan track precesses uniformly each day, while the location of the SAAMER foot- print is constant provided a sufficient number of meteors are detected. Note that for clarity we show only a single orbital pass of AIRS, rather than all passes over a day. In a complete day, the majority of the region should be covered at least twice.

We see large differences between the geographic coverage of the seven data sets. SAAMER has continuous coverage of a large proportion of the boxed region, with around 15000 individual meteor detections per day. AIRS has by far the best coverage of the satellites, with hundreds of individual measurements taken on every satellite pass; typically $\sim 8$ individual swaths overlap part of our region each day, each consisting of $135 \times 90$ spatially distinct measure- 

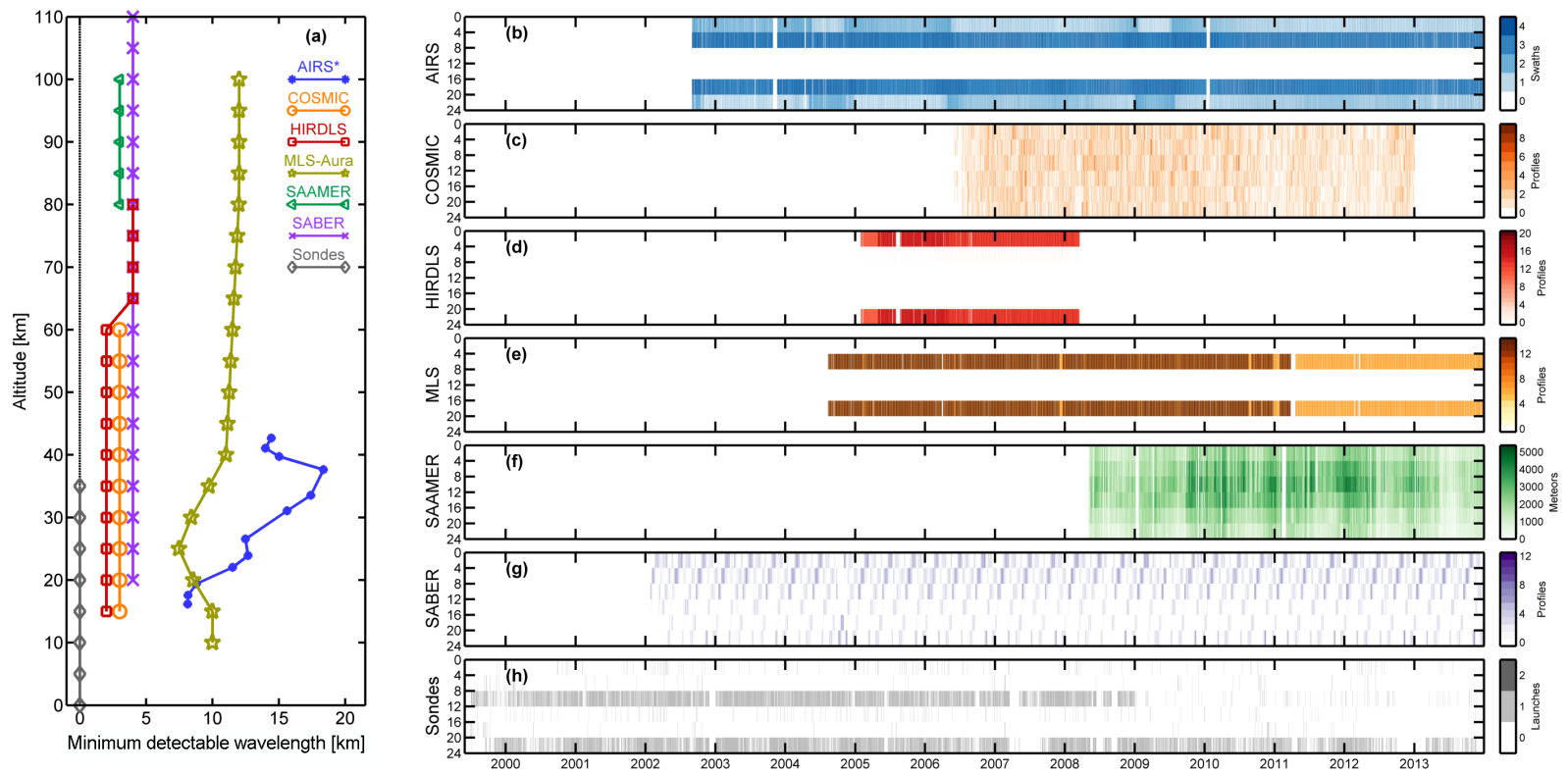

Figure 6. (a) Height coverage of each data set, with the approximate vertical resolution of each data set indicated at each altitude. Marker symbols are arbitrarily located and are only included to assist in uniquely identifying each series, with the exception of AIRS where they indicate the actual height levels analysed. (b-h) Temporal coverage of each data set. Each panel shows the number of measurements per $4 \mathrm{~h}$ period available for a given instrument for each day from 1999 to 2013, with time within each day on the vertical axis and days on the horizontal axis. Instrument are indicated by the text label at the left of each panel. All times are UTC.

ments at each height level. Of the limb sounders, HIRDLS has the best geographic coverage, with regularly repeating scan tracks crossing some part of the selected region almost every day. SABER will typically have several profiles in the region each day (but see Sect. 3.5 below for caveats relating to the yaw cycle), although much fewer than HIRDLS, and MLS-Aura has a similar number. COSMIC will also typically have several profiles per day. The example sampling shown for COSMIC is for a typical day late in the mission; during the earlier deployment phase, discussed above, profiles are instead often in closely spaced pairs or triplets (Hindley et al., 2015). Sondes are typically launched twice daily, and provide data from the region around Mt Pleasant, travelling up to $\sim 150 \mathrm{~km}$ downstream during their ascent. Under the prevailing low-altitude winds in this region, this downstream region usually extends eastwards from the Falklands, i.e. slightly outside our geographic region of interest, and the results should be considered accordingly.

\subsection{Altitudinal coverage}

Figure 6a shows the altitudinal coverage and the minimum detectable vertical wavelength (MDVW) of each data set, defined as twice the vertical resolution for all instruments except AIRS. Maximum detectable vertical wavelengths are defined by the method used for analysis in each case, and will be discussed in Sect. 4. Horizontal resolution, defined by the averaging line-of-sight of the instruments, varies depending on direction of the observation, and will be discussed further in Part 2. Note that the marker symbols are uniformly but arbitrarily located, with the exception of AIRS where they indicate the actual levels studied.

SABER has by far the best altitude coverage, extending from the lower stratosphere to well above $100 \mathrm{~km}$, with a constant MDVW of $\sim 4 \mathrm{~km}$. MLS-Aura has the next best coverage, from 10 to $100 \mathrm{~km}$, but with much coarser resolution at all heights. This is followed by HIRDLS, reaching from the tropopause to around $80 \mathrm{~km}$ altitude; this data set has a MDVW of $2 \mathrm{~km}$ up to around $60 \mathrm{~km}$ which then reduces to $4 \mathrm{~km}$ (Gille et al., 2013; Wright and Gille, 2013). COSMIC profiles reach up to $60 \mathrm{~km}$, with a MDVW of $\sim 2.8 \mathrm{~km}$ in the stratosphere (Tsuda et al., 2011).

SAAMER provides coverage in the region of the mesosphere in which meteor activity is significant: this activity is typically Gaussian-distributed about a peak altitude of $90 \mathrm{~km}$, with negligible observed meteor counts above $100 \mathrm{~km}$ or below $80 \mathrm{~km}$. The technique should be sensitive to comparatively small vertical features, with MDVW hard to define precisely but $\sim 3 \mathrm{~km}$ due to Fresnel reflection and altitude resolution limitations.

AIRS brightness temperatures are computed from $\sim 16$ to $\sim 42 \mathrm{~km}$ altitude. Due to the extremely deep weighting functions associated with AIRS' spectroscopic limb-sounding design, there is large and significant overlap between different height levels (Fig. 1a, discussed in more detail below). The values shown are the full widths at half maximum for each 
channel, below which we reject detected signals as spurious (Sect. 4.3) following the method of Alexander et al. (2009a).

The radiosonde data set covers the $0-35 \mathrm{~km}$ altitude range, although with an increasing probability of dropouts with height due to balloons reaching their peak altitude. Figure 2 shows the distribution of maximum heights achieved by the individual radiosondes, together with a minimum maximum height we require for a profile to be considered $(25 \mathrm{~km})$. In every month for which data are available, measurements exist above our cut-off, albeit occasionally only in small numbers. The MDVW of the measurements is $\sim 100 \mathrm{~m}$, much smaller than of the satellite data sets.

For all data sets, we omit the region around the tropopause, which we define as $10-15 \mathrm{~km}$; this is because the reversal of the vertical temperature gradient at this altitude induces a sharp kink in perturbation profiles. Data sets are analysed up to the highest altitude available in the data set in each case; this leads to the inclusion of both edge-truncated wave signals and/or lower quality data in the analysed results, which will be discussed where relevant.

\subsection{Temporal coverage}

Figure $6 \mathrm{~b}-\mathrm{h}$ show the temporal coverage of each data set. The vertical axis on each panel shows the subdiurnal availability of the measurements for each instrument, binned into $4 \mathrm{~h}$ periods after all quality checks have been made.

The longest data records belong to AIRS (Fig. 6a), SABER (Fig. 6g) and the radiosonde data set (Fig. 6h). AIRS and SABER launched in 2002, and are still operating, whilst the high-resolution sonde programme at Mt Pleasant commenced in 1999, albeit with gaps, particularly at later dates. SAAMER, which commenced operations in mid2008, is also still operating, as is MLS-Aura, which launched in 2004. COSMIC measurements extend from mid-2006 to date. HIRDLS has the shortest period of data, at around 3 years; note, however, that this 3-year period provides more individual wave measurements than the 11 years of SABER data (Wright et al., 2015). Due to being a fixed observational site, SAAMER makes measurements at all times of day. A daily cycle in the observed number of meteors is observed; this is due to the rotation of the earth relative to the Earth's travel vector along its orbit (Fritts et al., 2010). This effect is expected to slightly bias quantities averaged over periods longer than a day towards the subdiurnal periods of greater meteor density. There is also an annual cycle, due to zodiacal meteor clouds encountered as the Earth orbits around the Sun.

For all data sets, we use data up to the end of the calendar year 2013 where available and to the end of the available record otherwise.

AIRS, MLS-Aura, HIRDLS and the sonde measurements generally exhibit a consistent daily pattern, with two main passes over the region per day for HIRDLS, MLS-Aura and AIRS and twice-daily launches by the sonde station for most of the period considered. AIRS also exhibits coverage in the time bins on either side of the main passes, due to preceding or subsequent orbits to the primary pass clipping at least some part of the region most days. 11:00 UTC sonde data are not regularly available after 2008. There are often additional sonde launches in a given day; these are included in our analyses, but the final result will be dominated by the 11:00 and 23:00 UTC regular launches. SABER exhibits a precessing pattern, with the times of the regional overpass each day varying systematically with time.

\subsection{Discussion of coverage}

The data sets chosen complement each other well in terms of their geographic and temporal coverage. SABER provides coverage at a vast range of altitudes and a very long data record, but with a comparatively small number of profiles per day and with additional geographic constraints due to the satellite yaw cycle. MLS-Aura provides reinforced coverage over the full height range, but with a much reduced vertical resolution. HIRDLS provides a smaller, but still broad range of height levels, and has a much higher number of profiles per day but a shorter instrumental record. COSMIC provides additional limb-sounding coverage in the upper troposphere and lower stratosphere (UTLS), again with a long and continuing instrument record. AIRS again has a long and continuing data record and excellent horizontal detail, but with much reduced height discrimination. Finally, SAAMER provides detailed information on the upper mesosphere with continuous temporal coverage, and the sondes information on the troposphere with twice-daily coverage. The instruments also complement each other spectrally; this will be discussed in Sect. 5.

\subsection{Subregional effects of the SABER yaw cycle}

As mentioned in Sect. 2.6, SABER's scanning routine incorporates the TIMED spacecraft's yaw cycle, with the coverage region shifting north and south every 60 days to cover the poles alternately. Accordingly, while the coverage of the instrument in the tropics and at midlatitudes remains constant throughout the year, high northerly and southerly latitudes are only covered for approximately 60 days in every 120 days, with coverage in the "off" hemisphere extending to $\sim 51^{\circ}$ and in the "on" hemisphere to $\sim 87^{\circ}$. As shown by Fig. 7, this results in a geographic imbalance for SABER data at a subregional scale; while approximately the same number of profiles will fall within our region at all times of year, these profiles fall entirely in the equatorward quarter of the region during the northern yaw phase.

To assess the impact of this upon our results, Fig. 8 examines the impact of this geographic imbalance using HIRDLS data. Specifically, we divide the geographic region into two subregions, one poleward and the other equatorward of $51^{\circ} \mathrm{S}$, and investigate their relative temporal evolution. 

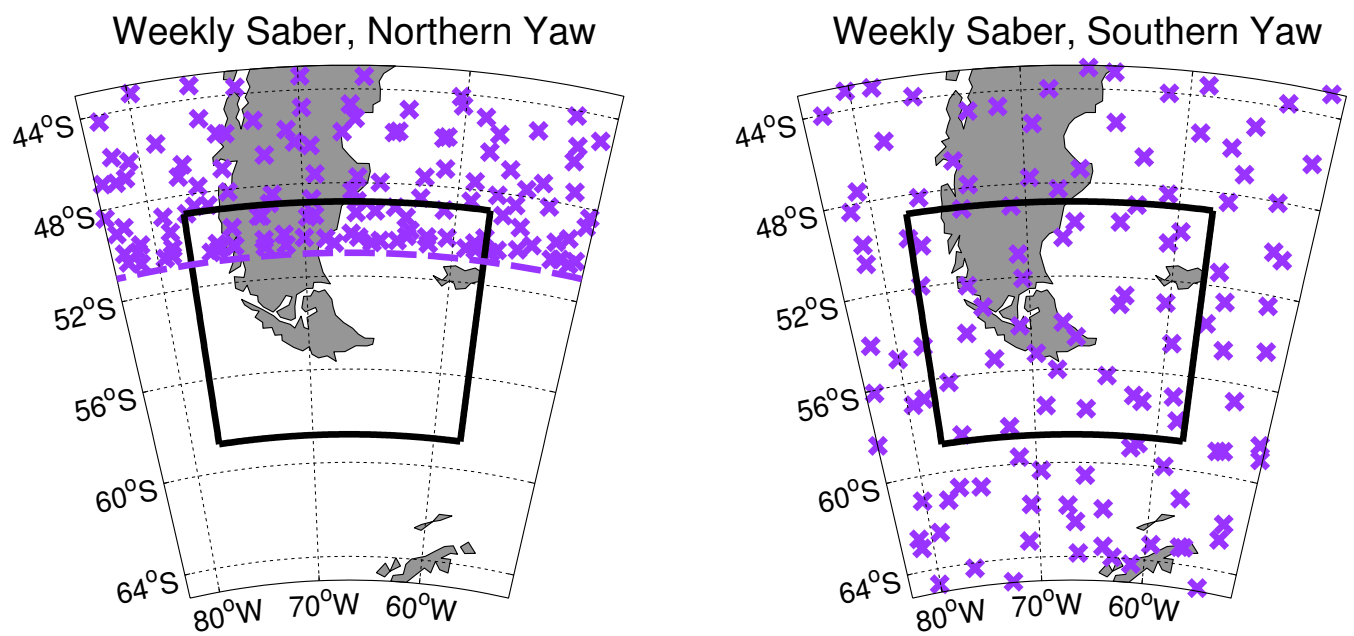

Figure 7. Typical weekly coverage for SABER during the northern (left) and southern (right) phase of the instrument yaw cycle. The dashed line in left panel indicates the approximate poleward limit of observations in this yaw phase. Note the greater observation density in the covered part of our region during the northern phase of the yaw cycle, due to the scan track turnaround near these latitudes. Specific coverage illustrated is from 1-7 March 2006 (left) and 1-7 January 2006 (right).
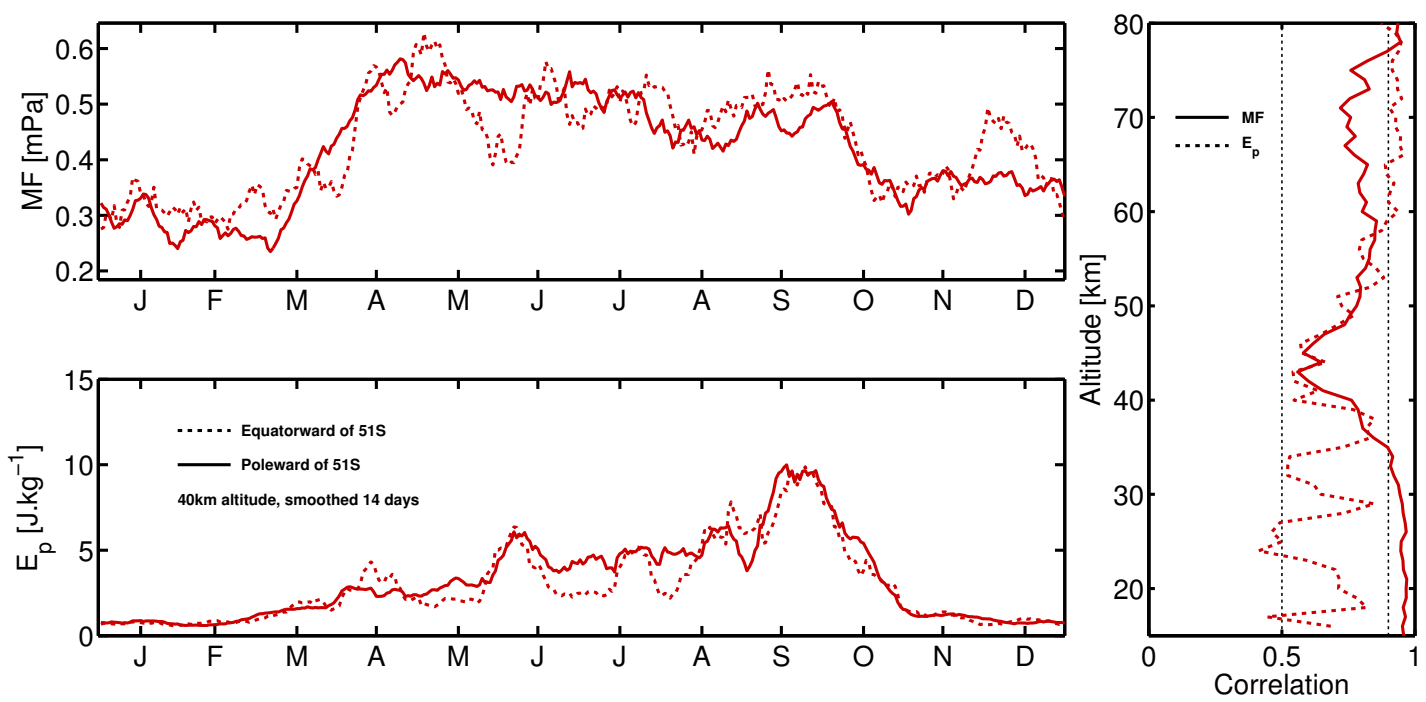

Figure 8. Annualised HIRDLS-derived (a) GWMF and (b) GWPE for the boxed region illustrated in Fig. 7, divided into (dotted) equatorward and (solid) poleward of $51^{\circ} \mathrm{S}$ regions. Data shown are at $40 \mathrm{~km}$ and smoothed by 7 days. (c) Pearson linear correlation ("c") between poleward and equatorward regions for (solid) GWMF and (dashed) GWPE annualised time series (smoothed 14 days) at each height level in the HIRDLS data set. $c=0.5$ and $c=0.9$ are indicated with dotted black lines for reference.

Figure 8a shows the annualised estimated GWMF and GWPE at $40 \mathrm{~km}$ altitude for the equatorward (dotted line) and poleward (solid line) regions. The calculation method for GWPE is discussed in Sect. 4 of this paper. The GWMF calculation is described in Part 2 and is that described by Wright and Gille (2013). Data have been smoothed by 14 days; this is because the short-timescale variation in the observed $\mathrm{GW}$ field is extremely large (e.g. Hertzog et al., 2012; Wright et al., 2013), and consequently there is significant and dominating variability at shorter timescales. We see a similar tem- poral evolution, with elevated GW activity levels during the period April-October and lower during the rest of the year. The equatorward results exhibit more volatility; this is consistent with the much smaller geographic region this represents, which will tend in the HIRDLS data set to contain a smaller number of profiles. Since the number of profiles remains approximately constant in SABER between the two yaw phases (Fig. 7), this volatility should be smaller for SABER relative to the southern region. 
Figure 8c extends this analysis to all height levels observed by HIRDLS. Here, the solid line shows the Pearson linear correlation coefficient between the two (14-day smoothed, annualised) time series at each altitude for (solid line) GWMF and (dotted line) GWPE. We see that correlation coefficients typically lie between $\sim 0.5$ and $\sim 0.9$ for both GWPE and GWMF. This is similar to or better than the correlations observed between HIRDLS GWMF and large-scale GWMF-generating processes such as the monsoon (Wright and Gille, 2011). It may hence primarily represent limitations in the GWMF sampling and calculations rather than inter-subregional differences. Note that the $40 \mathrm{~km}$ level shown in Fig. 8a and 8b exhibits a lower correlation than many other levels, and thus the examples shown are close to a worse-case comparison.

We hence conclude that the effect of the yaw cycle on the temporal variability of SABER observations in our region should be small. They may however be important at certain altitudes, and will be discussed in these contexts.

\section{Analysis methods}

In this study, we examine the GWPE and vertical wavelengths obtained from our data sets. Part 2 will investigate other wave properties. For the satellites and sondes, we define GWPE as

$E_{p}=\frac{1}{2}\left(\frac{g}{N}\right)^{2}\left(\frac{\hat{T}}{\bar{T}}\right)^{2}$,

where $g$ is the acceleration due to gravity, $N$ the BruntVäisälä (buoyancy) frequency, $\hat{T}$ the local temperature perturbation and $\bar{T}$ the background temperature. $N$ is computed directly from instrumental temperature and pressure data where possible, with gaps in low-altitude temperature and pressure in some data sets replaced by ECMWF operational analyses (ECMWF, 2015). $g$ is assumed to be equal to $9.8 \mathrm{~ms}^{-2}$. This is slightly higher than the true $g$ at the heights we consider, but consistently so for all data sets examined. In any case, variability in $g$ is much less than that in $N$, which should therefore dominate variations in the combined term. $\hat{T}$ is computed using Stockwell transform (Stransform) methods (Stockwell et al., 1996), as described individually below; in general, this will provide slightly lower estimates of GWPE than in many other studies where the absolute local perturbation to the background temperature is used. This is because we effectively use a lower-bound estimate of wave amplitude (Wright, 2010; Wright et al., 2015) rather than using the full wave cycles of a selection of waves and relying on bulk profile numbers to average out over the whole wave cycle (Alexander et al., 2008b); thus, our results will have a lower mean value.

The SAAMER radar makes statistical estimates of properties of the GW field for GWs measured within the meteorcollecting volume of the radar, which is an approximately cylindrical region over the radar $\sim 20 \mathrm{~km}$ deep and $\sim 300 \mathrm{~km}$ in diameter. The radar measurements detect the wind perturbations associated with the GWs rather than their temperature fluctuations. The measurements are dominated by the contributions made by GWs with wave periods less than $\sim 3 \mathrm{~h}$ and wavelengths smaller than the approximate physical size of the collecting volume (Hocking, 2005). We reiterate here for clarity that the radar technique differs fundamentally from that used by the various satellites, as the product it produces is more closely related to gravity wave kinetic energy (GWKE) than GWPE (e.g Balsley and Garello, 1985; Geller and Gong, 2010). Our comparisons here will therefore be limited only to qualitative comparisons of the general form of the vertical structure and seasonal variability of GW variance and GWPE. Note, however, that the radar is also able to make simultaneous estimates of momentum flux and we will consider these measurements in Part 2.

\subsection{COSMIC, HIRDLS, MLS-Aura and SABER}

For the limb-sounding instruments, we compute $\hat{T}$ and $\lambda_{z}$ using vertical temperature profiles. We first detrend the observed data for sinusoidal global-scale wave features which wrap exactly around the latitude circle, which we assume to represent planetary waves. To do this, we take the global data from each instrument for each day, divide them into $5^{\circ}$ latitude bands, and for each band at each height level fit sine waves of modes one to three using the IEEE-1057 fourparameter wave-fitting algorithm (Händel, 2000). We then remove these waves, together with the corresponding zonal mean value, from our profiles, leaving profiles of the local perturbation to the mean atmospheric temperature, which we assume to be due to gravity waves. There will be some leakage of tidal features into the wave spectrum at mesospheric altitudes, since migrating and non-migrating tides will not necessarily alias to planetary-wave modes.

We next apply the Stockwell transform to the detrended vertical profile data. This method has previously been applied to compare data from COSMIC, HIRDLS and SABER by Wright et al. (2011), on a global basis but over a much narrower altitude range. Consistently with Wright et al. (2011) and also with Alexander et al. (2008a), we assume the single largest-amplitude signal at each height level to be a gravity wave. This assumption is reasonable in this region due to the dominance of the observed wave spectrum by large individual waves (Hertzog et al., 2012; Wright and Gille, 2013; Wright et al., 2013), and also allows simpler intercomparison between our data sets since the largest-amplitude signals will tend to be at the longer vertical wavelengths accessible to most of our instruments (see e.g. Fig. 8b of Wright et al., 2015 for evidence of this in the context of global HIRDLS measurements). It will, however, result in a bias of our results on average towards longer vertical wavelengths.

The transform output provides us with the amplitude $\hat{T}$ and vertical wavelength $\lambda_{z}$ of this dominant wave. Observed 
$\lambda_{z}$ values are quantised as integer multiples of the minimum detectable wavenumber, but due to the spectral width of the peaks other real values will map onto these. $\hat{T}$ is then used to calculate GWPE, whilst $\lambda_{z}$ is considered separately. We limit $\lambda_{z}$ to $\leq 30 \mathrm{~km}$; in practice, due to the quantisation of the S-transform output, this becomes $18 \mathrm{~km}$.

\subsection{Radiosondes}

For the radiosondes, we again compute $\hat{T}$ and $\lambda_{z}$ using vertical information. However, we do not have global data available for this data set, and accordingly we use a lineardetrending method to remove larger-scale structure, specifically a second-order Savitzky-Golay filter (Savitzky and Golay, 1964) applied to the individual profiles. This is a low pass filter by design, which we use as a high pass filter by differencing the original and output signals. The filter is applied with a frame size of $5 \mathrm{~km}$; the resulting transfer function provides a transmission factor of $>\sim 0.75$ for all vertical wavelengths shorter than $3.5 \mathrm{~km}$, dropping to 0.5 at $4.2 \mathrm{~km}$ vertical wavelength and 0.2 at $5.5 \mathrm{~km}$ wavelength (see Fig. 6 of Hindley et al., 2015, for an example of the second-order Savitzky-Golay transfer function for a frame size of $18 \mathrm{~km}$ ). This should adequately filter out the large-scale background temperature structure of the atmosphere, and should also serve to filter out the majority of planetary-wave signals as these typically have long vertical wavelengths at these latitudes. In practice, due to S-transform output quantisation, this limit of recorded wavelengths becomes $\sim 3 \mathrm{~km}$.

After detrending, our analysis follows the same methodology as the limb sounders, described in the second paragraph of Sect. 4.1.

\subsection{AIRS}

For AIRS, we compute the brightness temperature $T_{B}$ at each of the pressure levels specified in Table A2 of Gong et al. (2012). Brightness temperature for each individual radiance channel $i$ is computed as

$T_{B i}=\frac{h c k_{r}}{k_{B}}\left(\ln \left(\frac{2 h c^{2} k_{r}^{3}}{R}+1\right)\right)^{-1}$,

where $h$ is Planck's constant, $c$ the speed of light in vacuum, $k_{B}$ Boltzmann's constant, $k_{r}$ the wavenumber associated with the radiance channel, and $R$ the measured radiance. The brightness temperature used at each level is then computed as the unweighted mean of the contributing channels at that level, i.e.

$T_{B}=\frac{1}{n} \sum_{i=1}^{n} T_{B i}$

for $n$ contributing channels. We detrend the resulting $T_{B}$ data across-track with a fourth-order polynomial for each AIRS granule (Alexander and Barnet, 2007; Alexander et al., 2009a; Alexander and Grimsdell, 2013), leaving perturbations around the local brightness temperature $T_{B}$.

These perturbations show clear evidence of wave-like signatures when examined individually. However, they underrepresent the true amplitude of the observed waves, due to the broad kernel functions used in the AIRS retrieval. To compensate for this, we convolve the kernel function of each channel with a vertical sine wave of known wavelength and amplitude unity, and iterate across all possible phases of the input wave, optimising for the best response as a function of phase. We repeat this over a broad range of wavelengths, normalise the results, and from this compute the attenuation response of an observed signal $A\left(\lambda_{z}\right)$ (Fig. 1a and b), rejecting all wavelengths smaller than the full width at half maximum of the kernel function. The function $A\left(\lambda_{z}\right)$ can in principle be used to scale the amplitude of the observed wave from a brightness temperature perturbation to a "true" temperature perturbation. However, since the response is a function of the vertical wavelength of the observed wave signal, we must first compute the vertical wavelength $\lambda_{z}$.

$\lambda_{z}$ is computed via reference to linear theory. We initially assume that the large-amplitude long-vertical-wavelength waves visible to AIRS in this region are orographic in source. Then, under the assumption that the waves observed thus have zero ground-based frequency and horizontal phase speed, vertical wavelength can be computed as (Alexander et al., 2009a; Wright, 2010)

$\lambda_{z}=2 \pi\left(\frac{N^{2}}{U^{2}}-k_{h}^{2}\right)^{-1 / 2}$,

where $U$ is the local wind speed projected along the wavevector and $k_{h}$ is the horizontal wavenumber of the observed waves.

To compute $k_{h}$, we follow the method of Alexander and Barnet (2007). First, we S-transform each across-track row of the AIRS granule, and then multiply the resulting spectrum for each row by the complex conjugate of the adjacent row to produce covariance spectra. We average these covariance spectra across all row pairs in the granule to produce a mean covariance spectrum for the granule, and extract up to five peaks in this averaged spectrum.

For each peak, we then extract the horizontal wavelength associated with the peak in the across-track direction and use the phase change between each row and the adjacent row at the appropriate frequency to compute the corresponding along-track horizontal wavelength for each pixel on the granule, together with the associated brightness temperature perturbation. Using the known geometry of the observations, we then rotate these into a rectilinear latitude-longitude coordinate system and combine them in quadrature after converting to wavenumber (via the identity $k=2 \pi / \lambda$ ). This produces an estimate of the horizontal wavenumber $k_{h}$ and brightness temperature amplitude $\hat{T}_{B}$ for each pixel for each of our up-to-five peaks. We separately compute an esti- 
mate of the magnitude of the local wind projected along the wavevector from ECMWF operational analyses, and use these quantities and Eq. (4) to compute $\lambda_{z}$ associated with this peak for each pixel according to the method presented in Alexander et al. (2009a). This allows us to compute the attenuation response $A\left(\lambda_{z}\right)$ and hence the "true" temperature perturbation for each pixel

$$
\frac{\hat{T}}{\bar{T}}=\frac{\hat{T_{B}}}{A\left(\lambda_{z}\right) \overline{T_{B}}},
$$

which can be used with Eq. (1) to compute GWPE. Some outlier spikes arise at this step due to regions of smallamplitude noise being amplified significantly by a short vertical wavelength "calculated" from the horizontal wavelengths associated with the noise in the S-transform analysis above. To compensate for this, we remove any amplitudes more than 5 standard deviations above the granule mean at this step. This only affects a very small percentage of granules, but can have a very significant effect where it does apply.

Finally, we combine the separate results for each peak into a single mean value for each pixel, with the contribution from each peak weighted by the amplitude of the perturbation for that pixel associated with that frequency peak.

In principle, this method is sensitive to very small horizontal waves at around the Nyquist limit for the instrument sampling. However, due to the strong dependence of our results on the observed horizontal wavenumber $k_{h}$, we wish to exclude the very smallest scales, since these may potentially be strongly affected by noise in the signal. For example, in the AIRS granule studied by Alexander et al. (2009a) (their Fig. 3) the observed momentum flux is dominated by a very small feature at the Nyquist limit for the granule, with momentum flux of order hundreds of $\mathrm{mPa}$. While this feature is clearly visible in the granule in question, we cannot be sure that this will hold for the very large number of granules we consider here without individual checks, and accordingly we wish to reduce the dominance of such features on the overall result. To do this, we pre-smooth our observed brightness temperatures with a boxcar of width 3 pixels in each direction. In the case of the Alexander et al. (2009a) granule, this reduces our observed GWMF to that of the larger-scale feature which dominates initial visual inspection of the granule, of order tens of $\mathrm{mPa}$. This choice thus reduces our maximum resolution and focuses our analysis on larger-scale features, reducing mean and median values by around an order of magnitude.

For the limb-sounding instruments and sondes, we select only the largest-amplitude signal at each height level. By analogy, we thus wish to select the largest value of AIRS GWPE for each swath and use this value for subsequent analysis. However, due to the analysis methodology, the maximal value in each granule is highly skewed by portions of the observed wave cycle where the phase leads to the highest amplitude. This effect is illustrated by Fig. 1c and d. Fig- ure 1c shows the (3-pixel-boxcar-smoothed) temperature perturbations associated with an AIRS granule measured on the 6 September 2003 over South Georgia island. This granule is the example considered by Alexander et al. (2009a), discussed above. Figure 1d shows the GWPE computed using our method, with line contours overlaid to indicate the location of the wave-like feature in the above panel. As we see, this is dominated by an extremely localised maximum which is highly elliptical along a region of maximum input signal magnitude (but not necessarily amplitude). This maximal value over-represents the GWPE associated with the wave, which must instead be averaged over the full cycle of the wave. To approximate this averaging without a significant increase in computational complexity, we smooth our granules after analysis with a smoother of width 10 pixels (Fig. 1e), and then take the maximum smoothed value over the whole granule as our representative GWPE value. As can be seen, this delocalises the resulting signal, spreading it over the region covered by the wave, and reduces the observed value to one more representative of the wave as a whole. This will tend to further reduce our final values for GWPE (and, in Part 2, GWMF) relative to other studies using similar methods. Finally, we empirically remove features with GWPE $<0.5 \mathrm{~J} \mathrm{~kg}^{-1}$, which appeared indistinguishable from noise in our subsequent analyses (not shown) and dominated the mean and median of the distribution due to their large numbers.

\subsection{SAAMER meteor radar}

To detect gravity-wave variances and momentum fluxes from SAAMER, we use the method of Hocking (2005).

First, we compute the background wind state. Meteors in the $15-50^{\circ}$ off-zenith angle range are binned into six nonoverlapping height bands (specifically, 78-83, 83-86, 86-89, 89-92, 92-95 and 95-100 km). Mean winds are then calculated for $2 \mathrm{~h}$ windows, stepping $1 \mathrm{~h}$. This is done individually in the zonal and meridional directions, using a horizontal least-squares fit to the observed radial velocities and assuming a zero vertical mean wind speed. Meteors with a radial velocity more than $30 \mathrm{~ms}^{-1}$ above or below the computed mean are excluded from this calculation to avoid significantly biasing the results.

We assume this $2 \mathrm{~h}$ mean wind field to include the effects of planetary waves, the diurnal and semi-diurnal tide, and other large-scale background effects, leaving small-scale perturbations to be analysed for gravity-wave signatures. To compute the effects of gravity waves, we therefore interpolate the computed mean wind field to the location of each meteor and remove it, leaving a radial velocity perturbation $v^{\prime}$. These radial velocity perturbations are then analysed using the matrix inversion method of Hocking (2005) to give estimates of direction-resolved gravity-wave variances and momentum fluxes. 
Here, we use the absolute wind variance $v$, which we define via

$v^{2}={\overline{\left.<u^{\prime} u^{\prime}\right\rangle^{2}}}^{2}+{\overline{\left.<v^{\prime} v^{\prime}\right\rangle^{2}}}^{2}$,

where $u^{\prime}$ and $v^{\prime}$ are the small perturbations to the wind velocity in the zonal and meridional directions, $v$ is the absolute variance, and the overbars indicate time averaging. This quantity is more comparable to our satellite measurements, which are also absolute due to methodological limitations.

\subsection{Post-analysis data treatment}

For all data sets, we discard any GWPE values below the 2nd percentile or above the 98th percentile of the annual distribution at each height level before subsequent analysis. This method is simple to implement, can be applied consistently across data sets, and on inspection of individual time series serves well to remove clear and apparent spikes without significantly affecting the distributions under consideration. It should be noted that these spikes may in principle be geophysical, and thus we may be removing real features with this filter that potentially contribute significantly to wave forcing.

After this filtering, we generally represent our distributions using their median values, except in those figures where we show the full distributions. This is due to the strong intermittency of the observed wave spectrum in this region, which leads to outliers dominating the mean (e.g. Hertzog et al., 2012; Wright et al., 2013; Alexander et al., 2015). For Sect. 6.1, equivalent results were computed using the mean (not shown) for the four limb-sounding data sets, and exhibited results similar in form, but typically increased in magnitude by $\sim 20 \%$.

\section{Spectral coverage and the observational filter}

Ideally, we would like to compare our various data sets directly, both for validation purposes and to extend beyond the height/time information available in any individual instrument record. However, even after allowing for geographic and temporal coverage issues, no single instrument can in practice observe the full spectrum of gravity waves present in the terrestrial atmosphere. Fundamental measurement technology limitations prevent any given instrument from viewing more than a small part of the extremely broad wavenumber and frequency spectrum of the true atmospheric gravitywave distribution, an effect known as the observational filter (Alexander, 1998; Preusse et al., 2000, 2008; Alexander et al., 2010; Trinh et al., 2015). Figure 9 (columns a-g) illustrates approximate observational filters for our individual data sets in terms of vertical and horizontal wavelength and intrinsic frequency $\hat{\omega}$. For each instrument, the best-case altitude for vertical resolution is shown, selected from Fig. 6a.

Dependence on wavelength is determined based upon the physical properties of each instrument's design combined with radiative transfer (Preusse et al., 2000, 2002) and weighting functional considerations. The observable range in $\hat{\omega}$ is determined by finding the maximal and minimal values of the gravity-wave dispersion relation (Fritts and Alexander, 2003):

$\hat{\omega}^{2}=\frac{N^{2}\left(k^{2}+l^{2}\right)+f^{2}\left(m^{2}+1 / 4 H^{2}\right)}{k^{2}+l^{2}+m^{2}+1 / 4 H^{2}}$.

Here, $N=0.02 \mathrm{rads}^{-1}$ is the Brunt-Väisäila frequency, $H=7 \mathrm{~km}$ is the approximate scale height in the stratosphere and mesosphere, $f$ is the Coriolis parameter at $54^{\circ} \mathrm{S}$, and $k$, $l$ and $m$ are the zonal, meridional and vertical wavenumber resolution limits for each instrument, as estimated above.

We see that the limb-sounding instruments (COSMIC, HIRDLS, MLS-Aura and SABER) have very similar observational filters, strongly sensitive to long horizontal and vertical wavelengths and to intrinsic frequencies well below the Brunt-Väisäila frequency (approaching or in some cases exceeding the inertial frequency). The maximum vertical wavelength in each case is $30 \mathrm{~km}$, as imposed by our analysis. AIRS is sensitive to a comparatively narrow range of all three properties, at long vertical and short horizontal wavelengths and comparatively high intrinsic frequencies. SAAMER, in contrast, is sensitive primarily to short horizontal and vertical wavelengths, but to an extremely broad range of intrinsic frequencies. Our radiosonde data set is sensitive to most horizontal wavelengths above $\sim 100 \mathrm{~km}$, while our analysis method allows vertical wavelengths up to $\sim 5 \mathrm{~km}$ to be detected.

Figure 9 (column h) combines the observational filters of all six data sets to highlight the similarities and differences between them. Considering first the lower panel, we see a significant overlap in vertical wavelength-intrinsic frequency space between the three higher-resolution limb sounders (COSMIC, HIRDLS and SABER) and SAAMER and, separately, a moderate overlap between HIRDLS, COSMIC, MLS-Aura and AIRS. The wavelength-intrinsic frequency coverage of our radiosonde data sets overlaps all instruments except AIRS and MLS. In the upper panel, SABER, HIRDLS, MLS-Aura and COSMIC strongly overlap; AIRS overlaps to a limited extent with HIRDLS, MLS-Aura and COSMIC; the sondes overlap with HIRDLS, COSMIC and to a limited degree SABER; the radar shows some overlap with COSMIC, HIRDLS, MLS-Aura and the sondes.

It should be clearly noted that the observational filter we show here is strictly an approximation for each instrument at best, and is critically dependent on many other factors, such as orbital geometry, tangent point averaging volumes, meteor count rates, etc. For example, limb sounders such as HIRDLS see the projection of a wave along their track rather than the true horizontal wavelength of the wave, and thus may see waves which have a true horizontal wavelength well outside HIRDLS' observational filter but which have an along-track projection within it (discussed previously by e.g. Preusse et al., 2000). 

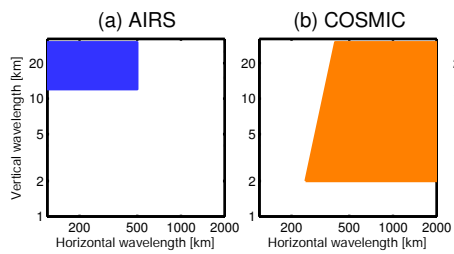
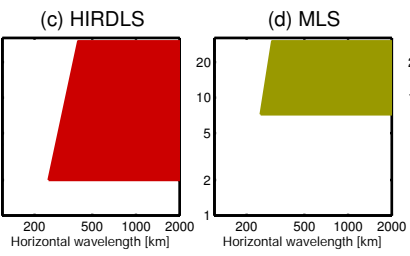

(e) SAAMER
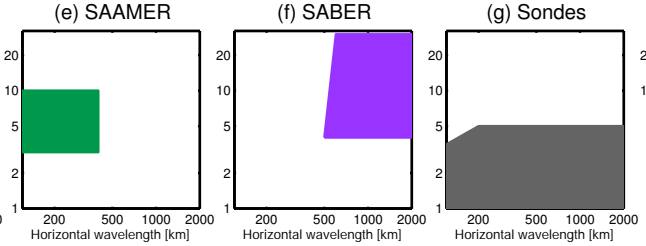

(h) All instruments
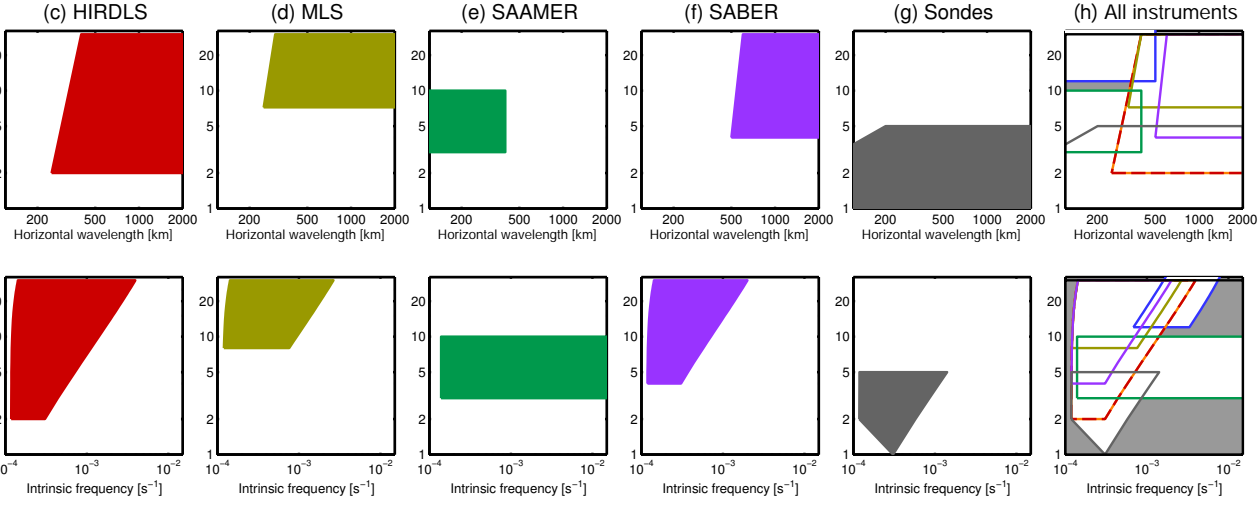

Figure 9. Approximate observational filters for the instruments considered, in terms of observable horizontal and vertical wavelengths (top row) and observable intrinsic frequencies and vertical wavelengths (bottom row). Based upon Alexander et al. (2010) and Preusse et al. (2008).

Furthermore, winds may Doppler shift the observed vertical and horizontal wavelengths of a wave, causing a given wave which is invisible at one height to become visible at another despite no change in the observational filter.

\section{Gravity wave potential energies}

\subsection{Variations with altitude}

\subsubsection{Annual median}

Figure 10a illustrates the all-time median GWPE measured by each of our data sets over their entire data records and over their full height ranges. Data are shown on a log-10 scale in GWPE. Diagonal light grey lines on all panels of Fig. 10 indicate a gradient of $\exp (z / 2 H)$ for reference. This gradient is consistent with free amplitude growth for non-dissipating waves. It should be clearly noted that, due to processes such as Doppler shifting, a given wave may be invisible to a given instrument at one height but visible at another as it shifts in or out of the observational filter for that instrument.

For comparison, Table 1 lists sample values obtained for GWPE or equivalent variables over this region in previous studies. Many of these values, primarily measured in the upper troposphere and lower stratosphere (UTLS), have been visually estimated by the authors from global or regional maps published in the original studies, and thus should be treated as highly approximate. Moffat-Griffin et al. (2013) observed values approximately $50 \%$ of ours using the same radiosonde data set at the 10 and $25 \mathrm{~km}$ altitude levels; this is consistent with the different background removal method. As Table 1 shows, beside general trends of seasonality and increase with height, these previous observations are extremely varied. This highlights the large magnitudinal differences between previous studies of waves in our data sets, which as we will later suggest appear to be primary methodological.
The dominant visible trend in our results is of a strong increase in observed GWPE with height. This is consistent with both the expected trend due to atmospheric density and with the previous literature at this and other locations (e.g. John and Kumar, 2012).

We see excellent agreement between HIRDLS, SABER and COSMIC at altitudes between 15 and $40 \mathrm{~km}$. Here, the gradient is higher than $\exp (z / 2 H)$, consistent with dissipation of wave energy with height. This is consistent with the very similar observational filters of these instruments. The gradient falls to $\sim \exp (z / 2 H)$ above $45 \mathrm{~km}$, suggesting much less dissipation in the upper stratosphere and mesosphere than in the UTLS. Importantly, we note here that the annual median here hides strong seasonal variations in dissipation, which will be discussed in Sect. 6.1.2.

COSMIC diverges strongly from HIRDLS and SABER above $40 \mathrm{~km}$ altitude. This is likely to be a combination of increased ionospheric noise preventing an accurate COSMIC retrieval and longer-vertical-extent gravity-wave signals near the top of the COSMIC data set being truncated and hence not resolved in our observations.

A similar tail-off, but with smaller vertical extent and a smaller fractional reduction, is seen at the top of the HIRDLS, SABER and higher-altitude radiosonde curves (in HIRDLS near $70 \mathrm{~km}$ in SABER near $100 \mathrm{~km}$, and in the radiosondes at around $25 \mathrm{~km}$ ). SABER also shows a slight reduction above $\sim 85 \mathrm{~km}$, but this is consistent with meteor radar observations in the same range and thus may be geophysical. This suggests that the majority of the drop-off in COSMIC is not due to edge truncation. Visual examination of the COSMIC data set (not shown) further suggests shows that COSMIC temperature is anomalously smooth at these altitudes by comparison to HIRDLS and SABER, so poorerquality data may well be the dominant reason for this dropoff.

The dependence of GWPE on height for MLS-Aura is quite different to the other limb sounders. There is good 

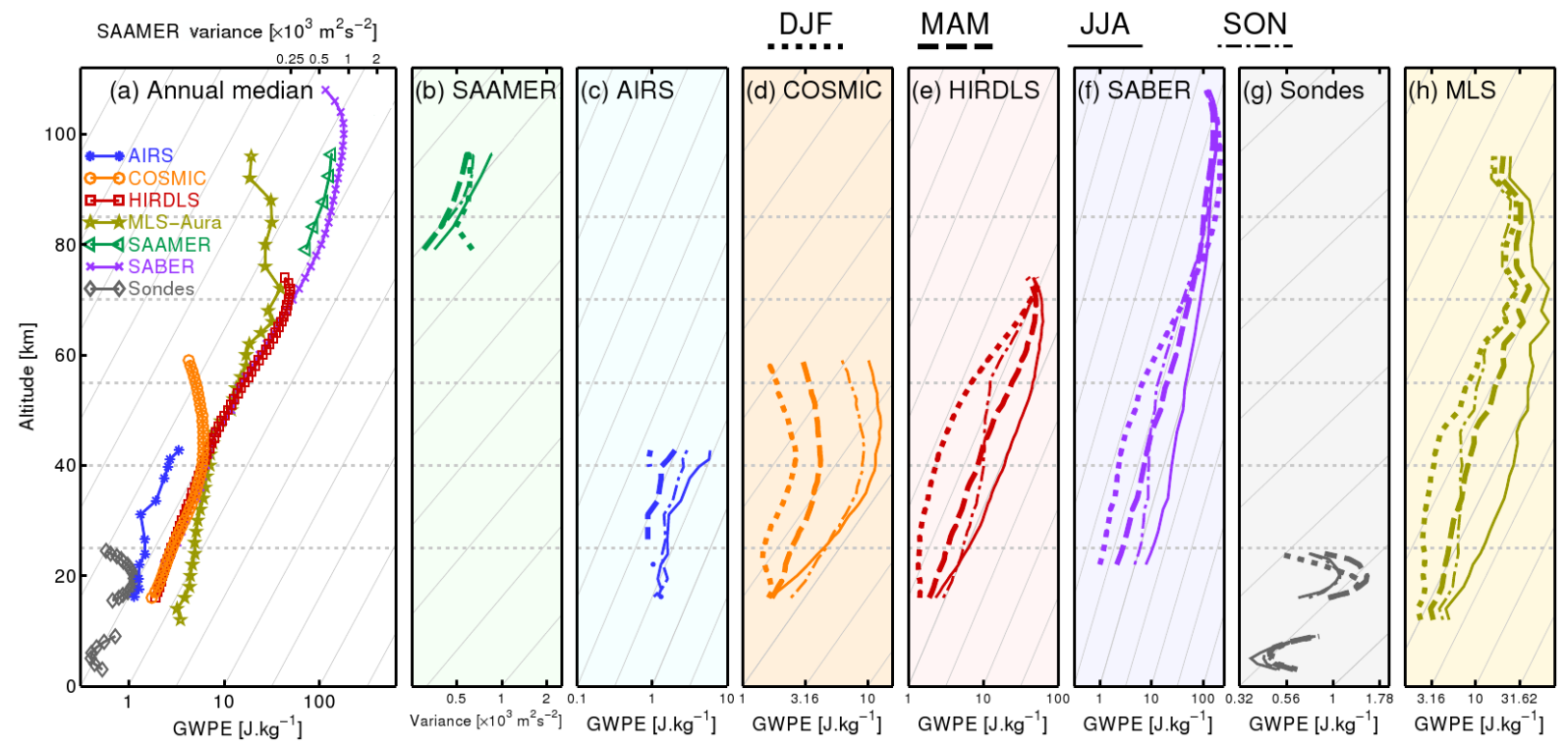

Figure 10. (a) Annual median GWPE (except SAAMER, variances, shown on top axis) observed by each instrument at each analysed height level. Grey horizontal lines indicate height levels studied in more detail later in this study. (b-h) Seasonal variability for each instrument.

Table 1. Sample literature values for GWPE in the region of interest, selected as the set of articles otherwise referenced in this study with values either provided in units of GWPE or equivalent convertable units (e.g. $T^{\prime}$ ). All values are highly approximate. Values originally published in terms of other quantities have been converted to GWPE by assuming $N=0.02$ and $g=9.81$, and deriving a mean background temperature $\bar{T}$ for the season of interest from ECMWF operational analyses.

\begin{tabular}{|c|c|c|c|c|c|c|c|}
\hline & \multirow[t]{2}{*}{ Study } & \multirow[t]{2}{*}{ Instrument } & \multirow[t]{2}{*}{ Height $(\mathrm{km})$} & \multicolumn{4}{|c|}{ Equivalent GWPE $\left(\mathrm{J} \mathrm{kg}^{-1}\right)$} \\
\hline & & & & DJF & MAM & JJA & SON \\
\hline A & Hei et al. (2008) & CHAMP & $12-33$ & 3 & 3.5 & 3 & 3.5 \\
\hline B & Alexander et al. (2015) (median) & COSMIC & $15-33$ & 0.5 & 0.75 & 0.75 & 1 \\
\hline $\mathrm{C}$ & Faber et al. (2013) & COSMIC & $20-30$ & 2 & & 5 & \\
\hline $\mathrm{D}$ & Hindley et al. (2015) (wave-ID) & COSMIC & $25-35$ & & & 22 & \\
\hline $\mathrm{E}$ & Hindley et al. (2015) (all) & COSMIC & $25-35$ & 3 & 4 & 5 & 6 \\
\hline $\mathrm{F}$ & John and Kumar (2013) (method 1) & COSMIC & $20-40$ & & & 16 & \\
\hline G & Ern et al. (2004) & CRISTA & 25 & & & 36 & \\
\hline $\mathrm{H}$ & Yan et al. (2010) & HIRDLS & $22-32$ & 1.2 & 4.1 & 4.7 & 5.4 \\
\hline I & Alexander et al. (2008a) & HIRDLS & $25-30$ & & & 3.8 & \\
\hline $\mathrm{J}$ & Sato et al. (2012) & Kanto model & 32 & 2 & 5 & 15 & 10 \\
\hline K & John and Kumar (2013) (method 1) & SABER & $20-40$ & & & 16 & \\
\hline $\mathrm{L}$ & John and Kumar (2013) (method 2) & SABER & $20-40$ & & & 3 & \\
\hline M & Alexander et al. (2015) (median) & SABER & $20-42$ & 3 & 10 & 18 & 18 \\
\hline $\mathrm{N}$ & John and Kumar (2012) & SABER & $20-60$ & 10 & 20 & 90 & 50 \\
\hline $\mathrm{O}$ & John and Kumar (2012) & SABER & $60-80$ & 20 & 30 & 120 & 30 \\
\hline
\end{tabular}

agreement between $\sim 40$ and $55 \mathrm{~km}$ altitude, but diverging to higher values at low altitudes and vice versa. Interestingly, the region of best agreement does not correspond to the altitude range below $40 \mathrm{~km}$ in which the instrument has the finest vertical resolution (Fig. 6a). The positive bias at low altitudes may be due to the longer-vertical-wavelength waves observed by MLS-Aura carrying larger temperature pertur- bations relative to the shorter ones accessible to HIRDLS, COSMIC and SABER (e.g. Wright et al., 2015, their Fig. 8c), or due to the comparatively weaker winds at these altitudes (our Fig. 3) leading to fewer large-amplitude waves being Doppler-shifted into the MLS-Aura observational filter relative to the finer-resolution instruments. The low bias in the mesosphere may also be associated with weaker winds and, 
in particular, the lower precision of temperature estimates here $(\sim 2.5 \mathrm{~K}$, of the same order as some of the waves studied).

AIRS results have a slightly steeper gradient than the limb sounders, i.e. a slower increase of GWPE with height. The height series is also moderately jagged, at least by comparison to other data sets at the same height. Both of these factors are consistent with the varying observational filter of AIRS with height. As shown by Fig. 6a, the minimum detectable vertical wavelength for AIRS increases with height, and is discontinuous between levels, both of which are reflected in this height distribution. Measured GWPE is lower than the four limb sounders, consistent with our analysis method which will tend to low-bias the results due to pre-smoothing of the granules. It is also consistent with the portion of the spectrum observed, which extrapolating from HIRDLS observations may have smaller amplitudes (Fig. $8 \mathrm{~b}$ of Wright et al., 2015).

SAAMER measurements exhibit an almost identical form to SABER at relevant height levels, albeit one with a less than $\exp (z / 2 H)$ gradient as seen at lower heights.

Finally, the radiosonde measurements exhibit initially odd-seeming concave and convex forms. This is likely due to the very short vertical extent of each series. Even using a vertical filter as short as $5 \mathrm{~km}$, the vast majority of each series is in an edge-truncated region, and is thus not very reliable. The values at the centres of the height ranges, which should not be edge-truncated with the filter applied, are consistent with an $\exp (z / 2 H)$ gradient, and also with the previous results of Moffat-Griffin et al. (2013) using this data set after allowing for the different background removal.

\subsubsection{Seasonal medians}

Figure $10 \mathrm{~b}-\mathrm{h}$ show seasonal medians for each instrument. Figure 11 shows the same data, but sorted as one panel per season rather than one per instrument to better illustrate multi-instrument seasonal variability.

Note that, due to a paucity of granules with measured GWPE above noise at many levels of AIRS for much of the year, the height range of the AIRS seasonal distributions (Figs. 10c and 11) varies. This will be discussed in more detail in Sect. 6.2.

We start our discussion in the troposphere and UTLS. The radiosonde observations (Fig. $10 \mathrm{~g}$ ) suggest that the highest values here are seen in autumn (MAM), with the lowest in winter (JJA). This is consistent with Moffat-Griffin et al. (2013), but does not correspond to the satellite data sets in the region of vertical overlap. In the satellite data sets, values in the lower stratosphere (below $\sim 25 \mathrm{~km}$ altitude) peak instead in either spring (SON, Fig. 11d) or winter (JJA, Fig. 11c), with spring values largest in AIRS, COSMIC and HIRDLS observations and winter values largest in SABER and MLSAura observations.
Throughout the middle and upper stratosphere, all instruments show the largest values of GWPE in winter (JJA). The springtime peak dies away in the mid-to-upper stratosphere in all data sets except COSMIC, and drops below autumnal values (MAM) above around $40 \mathrm{~km}$. As previously discussed, COSMIC data are less reliable at these altitudes.

In the stratosphere, the gradients of each individual season with height remain approximately constant, with the exception of spring, where the gradient diverges sharply from the exponential fit. This tallies with our seasonal wind median (Fig. 3), where the absolute median winds in spring similarly trend upwards until around $30 \mathrm{~km}$ altitude, above which they rapidly fall in magnitude. The wind also shows a very similar seasonal-median trend in the three other seasons, at least up to $\sim 70 \mathrm{~km}$ and perhaps higher. This may be consistent with either differential seasonal filtering of high phase-speed waves or waves being Doppler-shifted into the observational filters of the instruments.

As we enter the mesosphere, seasonal variations become much less dramatic in all data sets, as do wind variations. In particular, seasonal-median GWPE converges tightly at altitudes above $\sim 80 \mathrm{~km}$ in SABER, and gives the impression of converging at the top of the HIRDLS analysis range $(75 \mathrm{~km})$. The latter feature may be spurious, as the full annual cycle of HIRDLS GWPE looks very unusual at this altitude (Sect. 6.2) when compared to the other data sets. Finally, in the mid-mesosphere, all three instruments show the largest values in summer and winter, and smaller values in spring and autumn. This is consistent with previous observations at these altitudes, which show a strong semi-annual cycle of observed wave activity.

Wave dissipation, identified by the mismatch between measured gradients and the $\exp (z / 2 H)$ fit lines, is clearly seen, with strong seasonal variations. These variations are consistent across instruments, and are thus best discussed in the context of Fig. 11. The largest dissipation is seen in the upper stratosphere ( $\sim 40-60 \mathrm{~km}$ altitude) in spring (Fig. 11d), where the measured GWPE almost ceases to increase with height before resuming a positive trend. This region corresponds to one of very low absolute zonal winds (Fig. 3), suggesting strong critical-level filtering of orographic waves with zero phase speed from the Andes and Antarctic Peninsula.

We also see moderate dissipation in the UTLS in DJF (Fig. 11a), again corresponding to very low zonal wind speeds. Interestingly, the gradient above this region increases to one much larger than $\exp (z / 2 H)$; assuming the strong filtering of orographic waves in the UTLS consistent with our results, this may be indicative of waves moving into the region from outside or in situ sources.

We see minimal dissipation at any altitude in autumn (Fig. 11b). There is perhaps some dissipation at lower altitudes $(\sim 15-25 \mathrm{~km})$ in winter (Fig. 11c), but this does not correspond to any obvious wind effects. 

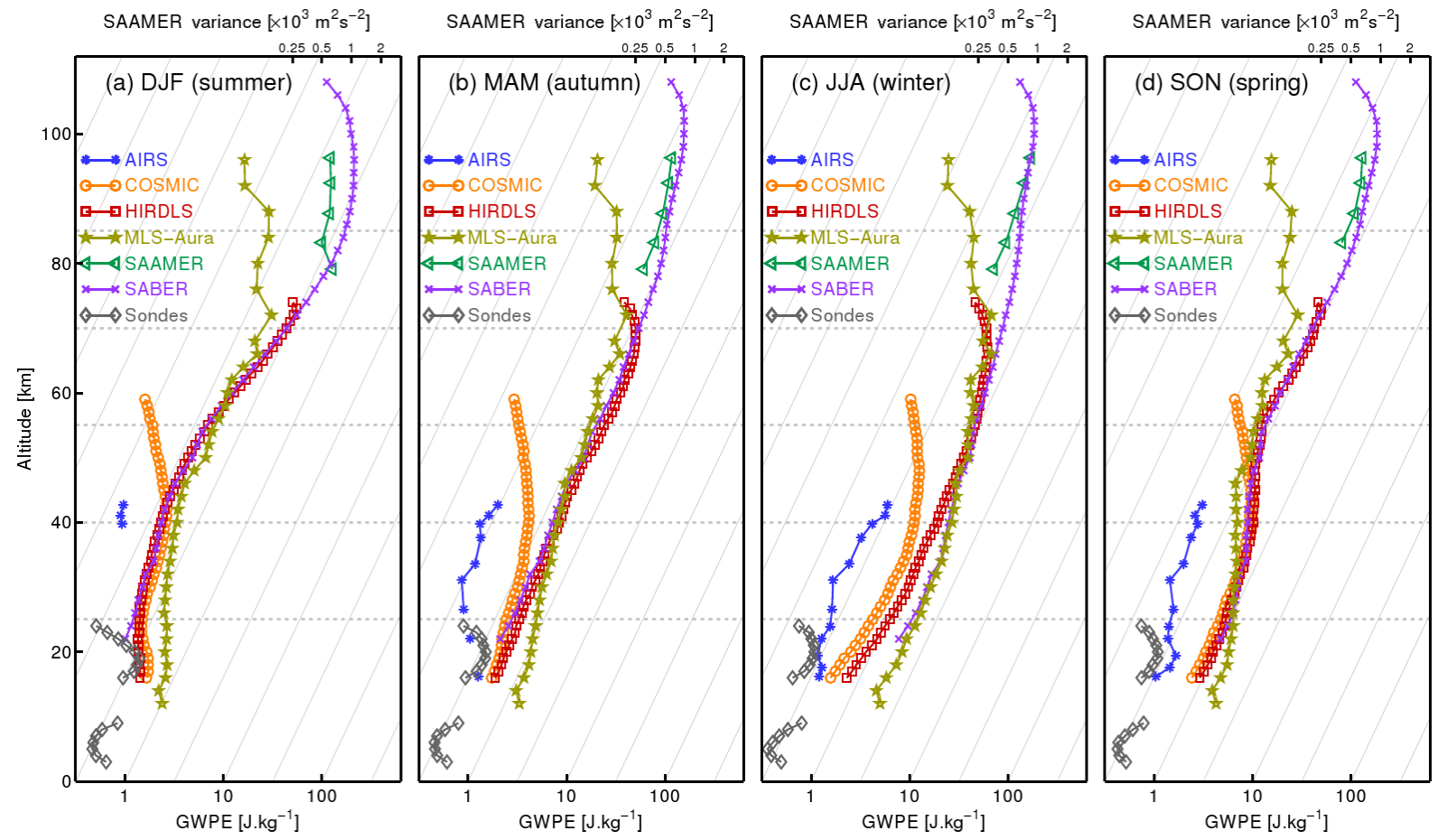

Figure 11. As Fig. 10, but sorted by season rather than by instrument.

In subsequent figures, we consider just the $25,40,55,70$ and $85 \mathrm{~km}$ altitude levels, indicated by the grey horizontal dashed lines in Fig. 10. This allows us to compare the variability of the different data sets more directly.

\subsection{Temporal variability}

Figures 12 and 13 consider the temporal variability of observed GWPE at these five specified altitude levels. Figure 12a-u show, for each instrument at each of our five height levels, the annual cycle (black dashed lines), interannual variability (coloured lines) and variability within all-years composite months (boxes and whiskers). Figure $12 \alpha-\epsilon$ reproduce the annual cycle for each instrument for ease of direct intercomparison. Finally, Fig. 13 shows unwrapped time series for each data set for the period 2002-2013. Figure 4 shows the winds corresponding to Figs. 12 and 13.

\subsubsection{Annual cycle}

We consider first the overall annual cycle, shown as black dashed lines in Fig. 12a-u and solid coloured lines in Fig. $12 \alpha-\epsilon$. Note that, with the exception of SAAMER, individual instrument data sets have been scaled to fit on a common vertical axis at each level. For each panel a-u, the values in the panel should be multiplied by the number indicated in the top right. The absence of a value indicates a multiplying factor of $1 \times$. Panels $\alpha-\epsilon$ are presented unscaled for all instruments.
Examining first SABER, MLS-Aura and SAAMER at $85 \mathrm{~km}$ (Fig. 12a, b, c, $\alpha$ ), we see a pronounced semi-annual cycle in GWPE, with peaks in summer (DJF) and winter (JJA). This is consistent with previous observations using meteor radars in the Antarctic region (Dowdy et al., 2007; Beldon and Mitchell, 2009). The summer peak is stronger in SABER, the winter peak is stronger in MLS-Aura, and both peaks are approximately equivalent in SAAMER. These differences may be related to the range of vertical wavelengths visible to each instrument (Sect. 7).

We next consider the $70 \mathrm{~km} \mathrm{level,} \mathrm{Fig.} \mathrm{12d,} \mathrm{e,} \mathrm{f,} \beta$. A clear annual cycle is seen in SABER and MLS-Aura, with high GWPE throughout April-September and low otherwise. SABER exhibits a slight peak around the year end, but this is very minor compared to the winter peak. HIRDLS has a less regular cycle and shows no significant correspondence with either MLS-Aura or SABER. This may be due to a combination of edge-truncated waves at the top of the HIRDLS analysis and lower-quality data at the highest altitudes due to instrument blockage effects, which are strongest here (Wright et al., 2015). Consequently, we remove this level from our subsequent analyses. This conclusion for HIRDLS is inconsistent with Wright et al. (2015), where wave patterns analysed using a variant of the technique used here appeared robust at the $70 \mathrm{~km}$ level. This difference most probably arises due to the use of single profiles here rather than paired-profile covariances in Wright et al. (2015), which will only allow 


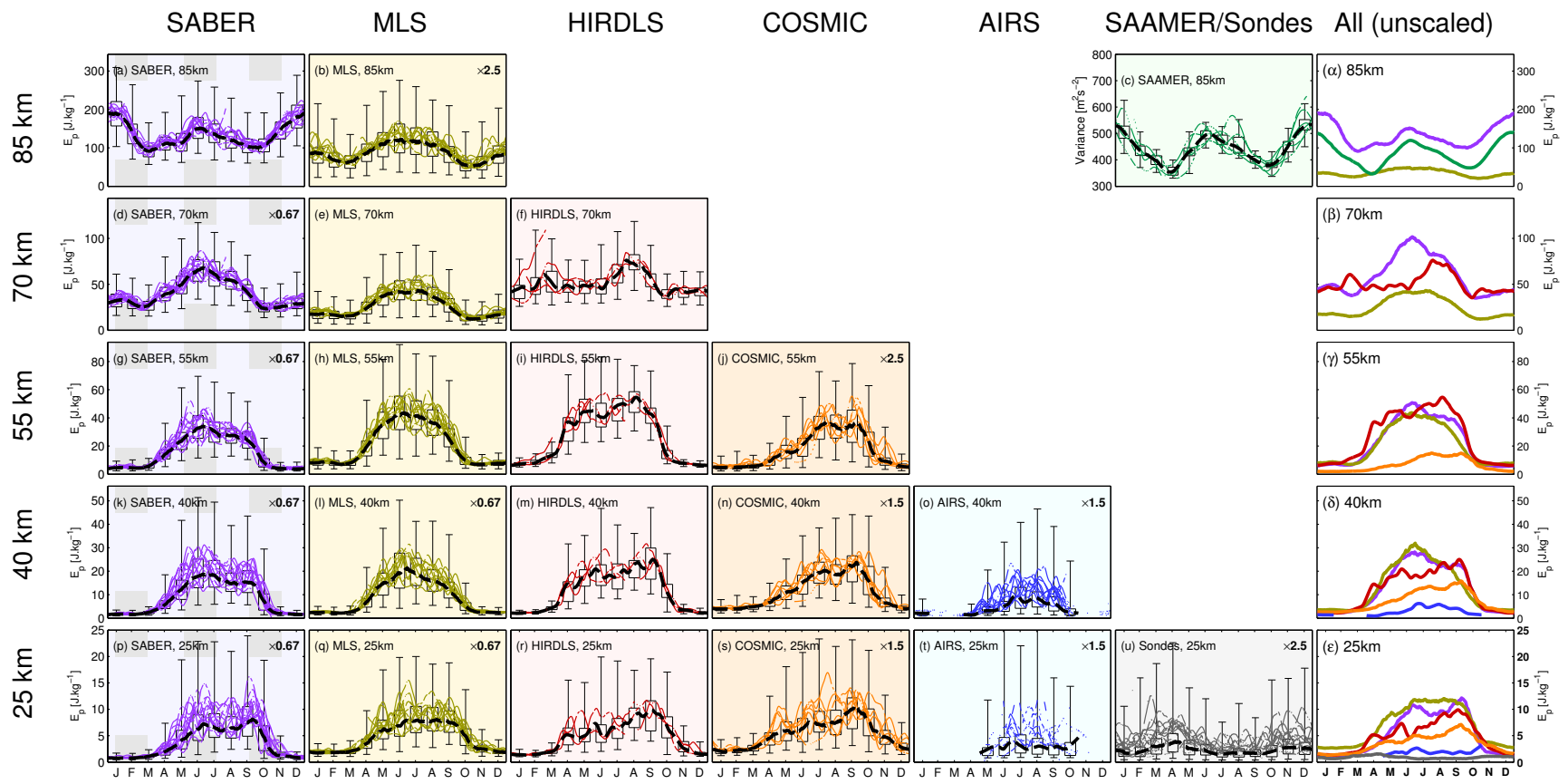

Figure 12. GWPE annual time series for each instrument at each valid height level. Each row of panels shows a single height level, and each column of panels shows the results for an individual instrument. Panels are only shown if data are present at that altitude for that instrument; AIRS and SAAMER share a column. For each panel, thinner lines show individual years, with the thicker black dashed line indicating the all-years mean.

noise to pass through to the final results if it covaries between adjacent profiles.

At the $55 \mathrm{~km}$ level (Fig. 12g, h, i, j, $\gamma$ ), HIRDLS, MLSAura and SABER show clear and strong annual cycles, with heightened GWPE from around April to September. COSMIC values are lower and exhibit a different form. This form is similar to that at lower altitudes in all four limb sounders. This may be due to the comparatively flat COSMIC distribution at high altitudes producing few positive wave detections, leading to vertically extended waves centred on lower altitudes dominating the S-transform output. This would further suggest that the COSMIC data quality is too poor for detailed use in studying gravity-wave effects at these altitudes. As with HIRDLS at $70 \mathrm{~km}$, we omit these data from subsequent analyses.

At the 25 and $40 \mathrm{~km}$ levels (Fig. 12k-t, $\delta-\epsilon$ ), the form for all four limb sounders shifts slightly. Whilst at $55 \mathrm{~km}$ the change between the low-GWPE summer state and the highGWPE winter state was comparatively abrupt, at $25 \mathrm{~km}$ all four limb sounders (with the possible exception of MLSAura) increase in intensity between April and September, with the suggestion of a small drop around midwinter. At the $40 \mathrm{~km}$ level, HIRDLS and COSMIC repeat this pattern, while SABER and MLS-Aura have a form more similar to the $55 \mathrm{~km}$ pattern. At the $25 \mathrm{~km}$ level, the annual cycle of all four limb sounders is similar to the wind (Fig. 4); at the $40 \mathrm{~km}$ level, the wind annual cycle is more similar to that of
COSMIC/HIRDLS than of MLS-Aura/SABER but not dramatically dissimilar from either. Again, this may be either a physical or an observational effect.

There are too few detected waves for useful analysis of AIRS for a large part of the year, with several months falling below our cut-off for analysis, defined as 30 total wave observations above our $0.5 \mathrm{~J} \mathrm{~kg}^{-1}$ noise level in that month over all years combined. Since AIRS observations observe only very long vertical wavelengths in high background winds (Alexander and Barnet, 2007; Alexander and Grimsdell, 2013), this perhaps suggests that such waves only become strongly visible during this part of the year. Allowing for this lack of data, AIRS appears to show a broadly similar form to COSMIC and HIRDLS at $40 \mathrm{~km}$, increasing through the autumn and winter. It is difficult to discern any pattern from the limited data at $25 \mathrm{~km}$.

Finally, the sonde GWPE (Fig. 12u) shows a larger peak in April and a smaller peak in November/December. This is very different to the other instruments, but reproduces the results of Moffat-Griffin et al. (2013) well in form. The radiosonde data set has an utterly different observational filter to the other instruments at this height level, with only a very small overlap with the limb sounders. This overlap is in practice even smaller than it appears theoretically in Fig. 9 due to the tendency of the limb sounder observations to be dominated by waves with larger $\lambda_{z}$ (see Sect. 7). These observations thus act as a stark reminder that the GWPE associated 


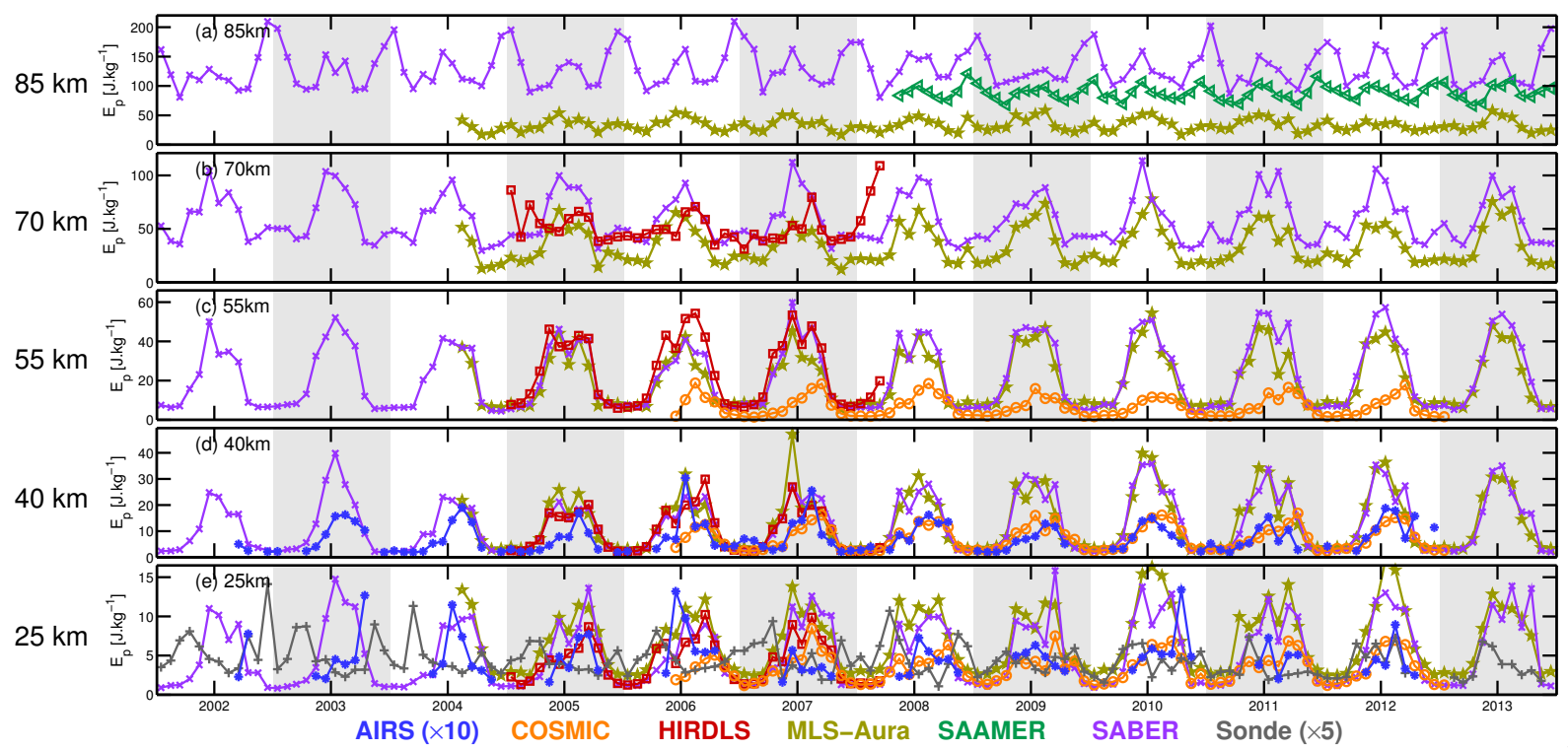

Figure 13. Time series from 2002-2013 of monthly-median observed GWPE for each of our instruments.

with waves in different spectral regimes will not necessarily be well correlated.

\subsubsection{Interannual variability}

The individual coloured lines in Fig. 12a-u show the daily median observed GWPE for each data set at each height for each individual year. The data have been smoothed 31 days to reduce the extremely strong day-to-day intermittency of the data sets. In all cases, the annual cycle in each individual year is broadly the same as the all-years median, with the same seasonal cycle. Interannual variability generally scales with the daily median of the all-years average; i.e. the interannual range on any given day is proportional to the all-years median for that day.

Figure 13 similarly shows little variability between years. There is perhaps some suggestion of the year-to-year variability of GWPE in the limb sounders being correlated with interannual variability in wind (compare to Fig. 4, discussed in greater depth in Sect. 6.3). Otherwise, no long-term (multiyear) pattern is seen.

\subsubsection{Intra-month variability}

The box-and-whisker plots in Fig. 12a-u show the composite-monthly variability of the data set. Specifically, each column shows the range of potential energies observed in that calendar month over all years, with the central box covering the range $32-68 \%$ and the outer whiskers covering the range 5-95\%. These values are chosen to correspond to the range covered by 1 and 2 standard deviations from the mean for normally distributed data. The median is by definition the same as the all-years median, indicated by the value of the black dashed line at the middle of each month, and is accordingly not separately indicated on the box-and-whisker plots.

All the data sets exhibit clear positive skews in their distributions, with the 68th and 95th percentiles lying much further from the median than the $32 \mathrm{nd}$ and 5 th. This is due to the approximately log-normal form of the observed GWPE distributions at each height, discussed in Sect. 6.4 below.

Except for SAAMER and possibly AIRS, distributions typically scale with their monthly median, with the positive skew leading to much larger variability in mean GWPE than the medians we examine here. For the six non-radar data sets, the 68th percentile typically has a value $25 \%$ larger than the median and the 95th percentiles $100 \%$ larger than the median. AIRS at $40 \mathrm{~km}$ is slightly different, in that the 95 th percentile shows a steady increase with time across the winter and peaks in September, while the median and the 68th percentile peak in July and fall away after this. Thus, the annual cycle of the distribution mean is somewhat different from that of the distribution median.

In SAAMER observations, we see a slight difference from the form of the previously discussed instruments. Variability does increase during the summer peak, but variability during the winter peak, while larger than that during spring and autumn, is smaller than would be expected following the uniform scaling seen elsewhere.

\subsection{Wind dependence}

Figure 14 shows scatter plots of absolute $\left(\sqrt{U^{2}+V^{2}}\right)$ wind against observed GWPE for each instrument at each relevant height level. Specifically, for each panel, the horizontal axis shows measured monthly-median GWPE and the verti- 

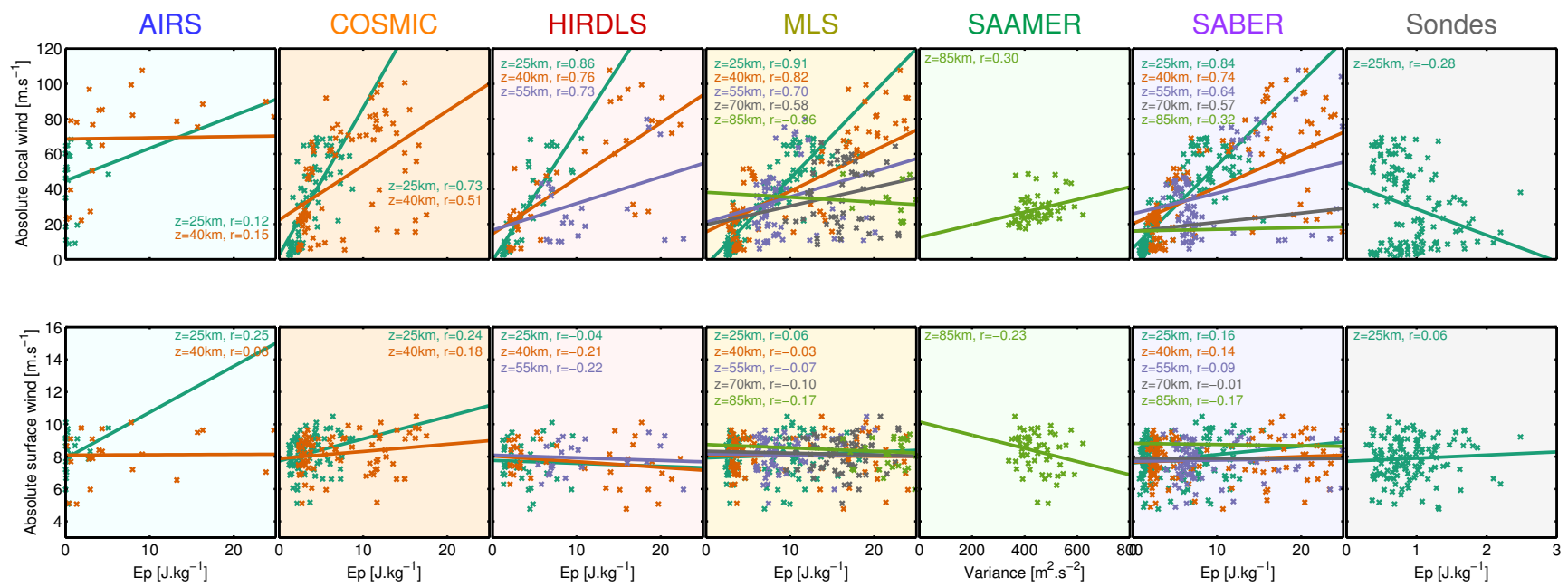

Figure 14. Scatter plots of observed GWPE against absolute wind speed for each height level. $[r]$ indicates the Pearson correlation coefficient at each level.

cal axis monthly-median absolute wind, with each cross indicating a specific month. Note that these are median reanalysis winds rather than observed winds, except at the $85 \mathrm{~km}$ level where they are median observed winds. The top row shows results for wind at the same level as the GWPE measurements, whilst the bottom row shows wind surface wind. We use wind data from 2002 to $2013(2006-2013$ at $85 \mathrm{~km}$ ), and thus radiosonde measurements from before 2002 (2006) are not included in this analysis.

For each instrument, we show all height levels at which the data sets overlap on the same panel to avoid the necessity for an extremely large number of panels to be plotted, with the different height levels indicated by colour. Solid lines show linear fits to the data at a given level, indicated by the same colour. In order to optimise the scales on each panel to make the largest possible subset of the data clearly visible, some panels do not show the individual scatter points for large values of GWPE, which is particularly a problem at high altitudes; logarithmic scales were investigated, but did not provide sufficient visual discrimination within a given level. For each level for each instrument, we also compute the Pearson linear correlation coefficient, $r$, indicated on the panels.

Considering first the upper row, we see strong correlations between measured GWPE and the local wind speed for all four limb sounders at low altitudes. The correlation with wind breaks down for MLS-Aura at the $85 \mathrm{~km}$ level, but otherwise, the correlation coefficients for all four limb sounders decline with height, from a very strong 0.91 for MLS-Aura at $25 \mathrm{~km}$ to a weak 0.32 for SABER at $85 \mathrm{~km}$. SAAMER also shows a weak 0.32 correlation with local wind.

Once again, the radiosondes and AIRS exhibit very different trends to the limb sounders. AIRS exhibits no meaningful correlation (0.12-0.15) at either level, while the $25 \mathrm{~km}$ radiosonde data set is weakly anticorrelated with the $25 \mathrm{~km}$ wind.

Surface winds (lower row) show no significant correlation with any data set at any altitude. This will be discussed further in Sect. 8.3.

\subsection{Seasonal histograms}

Figure 15 shows the full distribution of observed GWPE values at each altitude as a histogram. The all-years total histogram is shown in the leftmost column (Fig. 15a-e) and seasonal differences from this are shown in the other four columns (Fig. 15f-y). Each row represents a height level. With the exception of AIRS, where we do not measure the full annual cycle, all data sets have been truncated to remove partial years, in order to remove any seasonal bias from the annual-total histogram.

For the annual-total histograms, values are shown as a percentage of the total observations made. For the seasonal difference columns, they indicate the relative difference, i.e. the difference between the percentage in a given bin for that season and the percentage in that bin in the annual-total.

All histograms except SAAMER are shown on a common (logarithmic) horizontal scale to illustrate the shift of the distribution with height.The relative position of the SAAMER histogram is arbitrary, and is chosen to allow comparison with SABER without overlapping so closely as to become invisible. Data have been binned into 33 bins of equal width in $\log$ space across the range $10^{-1.5}-10^{3.0} \mathrm{~J} \mathrm{~kg}^{-1}$ at all heights (SAAMER: 33 log-spaced bins across the range 50$800 \mathrm{~m}^{2} \mathrm{~s}^{-2}$ ), and the histograms are presented unsmoothed other than this binning. Note that we previously removed all AIRS GWPE values below $0.5 \mathrm{~J} \mathrm{~kg}^{-1}$, and consequently values below this do not occur in the AIRS histograms. 


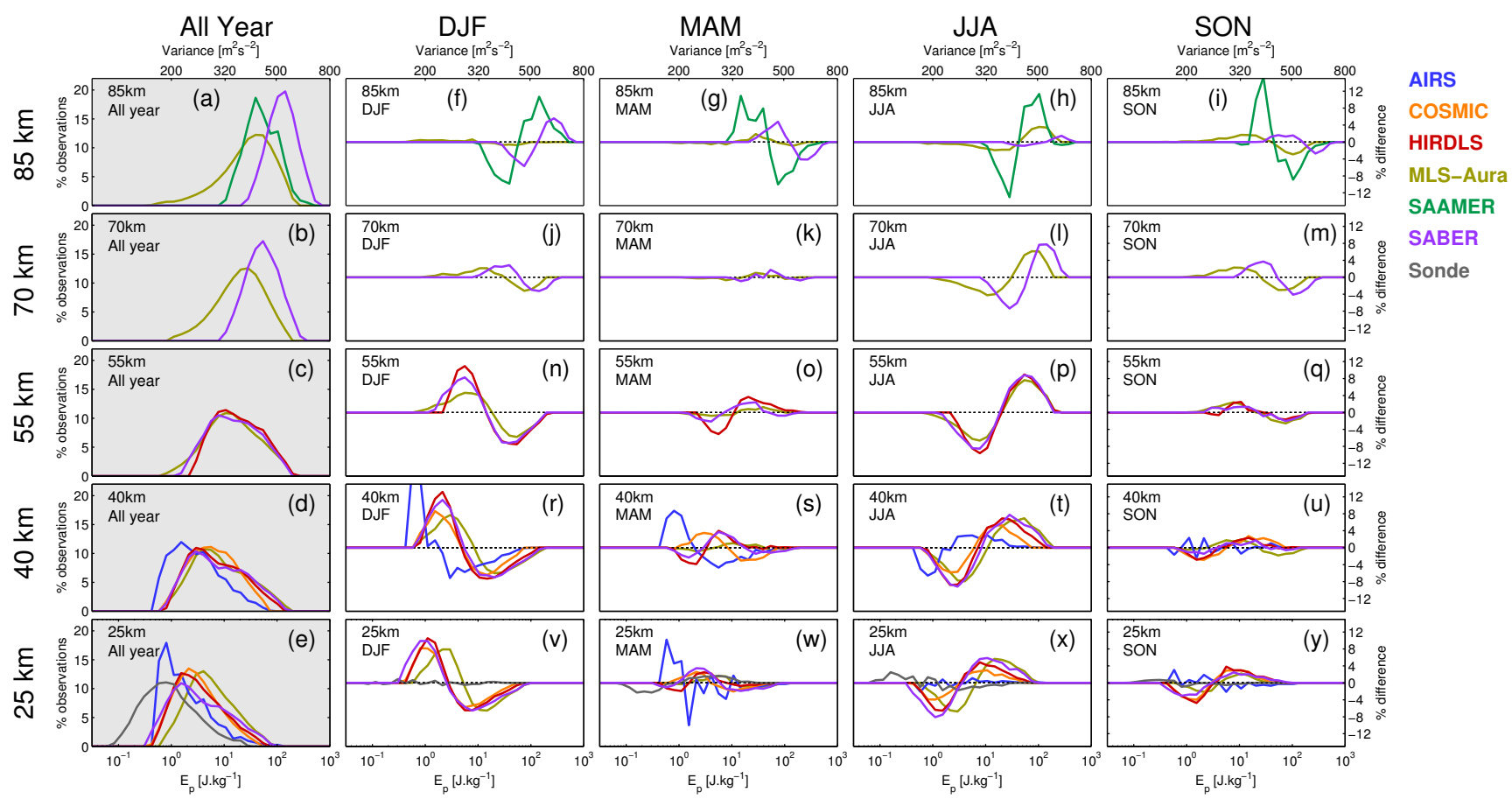

Figure 15. Percentage histograms of observed potential energies for all instruments at all levels. The leftmost column (a, f, k, p, u) shows histograms of all data considered, normalised to sum to $100 \%$. Remaining panels show differences between the normalised distribution for each season and the annual mean normalised distribution at that high level, as a percentage difference. SAAMER variances use the top horizontal axis; all other histograms use the bottom horizontal axis.

\subsubsection{Annual histograms}

We discuss first the annual histograms, Fig. 15a-e. In almost all cases, these form near-Gaussian distributions on our logarithmic GWPE axis, suggesting a log-normal form to the observed data. This is consistent with momentum flux observations in this region (Hertzog et al., 2012; Wright et al., 2013) and potential energy observations over the nearby Antarctic continent (Baumgaertner and McDonald, 2007), and suggests that GWPE in the atmosphere also follows this form at least in this region. There is some skew towards larger potential energies, perhaps due to the methodological bias towards larger events.

The limb sounders generally exhibit near-identical histograms to each other at each height level, with the exception of MLS-Aura at $55 \mathrm{~km}$ and above, where a tail at lowGWPE is seen. For each instrument, again with the exception of MLS-Aura above $55 \mathrm{~km}$, the distribution as a whole shifts towards larger GWPE with height. SAAMER is almost identical in form to SABER, with the exception of a slight drop at $\sim 500 \mathrm{~m}^{2} \mathrm{~s}^{-2}$, which may just be noise.

The sonde GWPE distribution is of the same form as the limb sounders, but shifted towards lower values. This is consistent with an association between shorter vertical wavelengths and smaller amplitudes (e.g. Wright et al., 2015), and suggests that the log-normal form of the GWPE distribution is consistent over a broad range of vertical scales.

Finally, AIRS exhibits a similar form to the other instruments insofar as the data extend, but with the caveat that at the $25 \mathrm{~km}$ level the distribution is truncated by our noise floor, and thus cannot be confirmed to maintain this form at low GWPE.

\subsubsection{Seasonal variability}

Seasonal variations are examined in Figs. 15f-y, with each column representing a season and each row a height level.

Since the histograms are normalised to sum to $100 \%$, seasonal variability in our figures by definition manifests itself as a shift within each histogram rather than as an absolute increase or decrease in the total histogram area. An increase (decrease) in the median observed GWPE will thus appear as a positive (negative) increase in the portion of the histogram lying above the annual median, and vice versa. This effect is clearly seen in the majority of the histograms, generally smoothly but with noise in some cases, particularly AIRS.

At all altitudes up to $70 \mathrm{~km}$, we see the clear seasonal cycle seen previously in Sect. 6.2.1 duplicated, with a clean reduction (increase) in the low-(high-)GWPE region of each histogram. Thus, the seasonal cycle we observed above is due to a uniform shift of observed GWPE to higher magnitudes 
rather than a change in some specific part of the distribution. This is consistent with the box-and-whisker plots in Fig. 12.

The $85 \mathrm{~km}$ level is slightly more complicated due to the semi-annual cycle of GWPE at this height, but is again consistent with the previous sections and indicative of a uniform shift in the distribution.

\subsection{Scatter plots}

Figure 16 shows scatter plots of monthly-median GWPE for each instrument pairing, with each cross indicating the median for the same month and year from the corresponding data sets.

Within each panel, the dashed black line indicates a theoretical $1: 1$ correspondence between the two data sets, with individual coloured lines corresponding to a linear fit between the two data sets as observed. As with Fig. 14, we show all levels on a single panel, with some data off axis. Above each panel we indicate for each height level the gradient $(m)$ and intercept $(c)$ of the fit line, together with the correlation coefficient $(r)$ of the observations. Height levels at which one or the other data set does not provide measurements are indicated by dashes, and panels are not shown if there is no height level at which the data sets overlap (e.g. radiosondes and SAAMER). No significance is assigned to the ordering of the panels.

We first take a broad overview, before examining individual pairings individually. Limb-sounder pairings generally exhibit excellent fits and high correlations, at least over the height ranges at which they operate optimally. Correlation coefficients are typically $>\sim 0.8$ in these cases, with fit gradients between 0.75 and 2 and small intercept values. Particularly good correspondences are seen at $25 \mathrm{~km}$, where all limb sounder combinations exhibit $r>0.85$, with the exception of MLS-Aura and COSMIC (panel m, 0.80).

Radiosonde measurements show very poor agreement with any other data set, consistent with their very different seasonality as seen above. Indeed, fit gradients in all cases are zero or near-negative, and correlation coefficients are extremely low or negative. This suggests a very significant disconnection between the wave processes observed by the radiosonde observational filter and those of any other instruments. Since this poor fit includes AIRS (panel h), which has a very high horizontal resolution, this suggests that the very different observed seasonality is due to environmental effects on wave vertical scales rather than horizontal, or at least a combination of the two scalings.

AIRS also exhibits a poor correspondence with all other instruments, with negative and near-zero correlations and fit gradients at the $25 \mathrm{~km}$ level. There does appear to be a moderate correlation ( $r=0.35$, panel 1 ) between MLS-Aura and AIRS at the $40 \mathrm{~km}$ level; this is the closest-vertical-resolution pairing available to AIRS and it is thus encouraging that this shows the best agreement. The next best agreement is with SABER ( $r=0.22$, panel $\mathrm{j})$, reinforcing this further.
The SAAMER radar shows excellent correlation with SABER, with $r=0.75$. The fit gradient and intercept are not meaningful here, due to SABER measuring temperature and SAAMER wind. MLS-Aura shows a poorer agreement, with $r=0.36$; this is consistent with the relatively poor highaltitude performance of MLS-Aura seen above.

We now very briefly consider each individual pairing, in panel order. This will be done in a bulleted format for brevity. We define a "very weak" (anti)correlation as between $(-) 0.20$ and $(-) 0.30$, a "weak" correlation as between $(-) 0.30$ and $(-) 0.50$, a "good" correlation as between $(-) 0.50$ and $(-) 0.75$, and an "excellent" correlation as greater (less) than $(-) 0.75$.

a. HIRDLS and COSMIC show excellent agreement at all altitudes, with $r>0.7$ at all levels. Fit gradients are all greater than 1 and increase with height; this corresponds to larger values of GWPE measured by HIRDLS, consistent with Fig. 6.1.

b. COSMIC and AIRS exhibit no significant correlation, with $r$ and $\mathrm{m}$ both $\sim 0$ at the two overlapping height levels.

c. Radiosondes and HIRDLS appear weakly anticorrelated, with $r=-0.37$.

d. Radiosondes and COSMIC exhibit no significant correlation.

e. SABER and COSMIC exhibit an excellent positive correlation, with $r>0.8$ at 25 and $40 \mathrm{~km}$. As with the HIRDLS-COSMIC pairing, observed values are lower with COSMIC, with a fit gradient $\sim 2$ at all levels.

f. HIRDLS and AIRS exhibit no significant correlation at $40 \mathrm{~km}$, and a weak anticorrelation $(r=-0.34)$ at $25 \mathrm{~km}$.

g. Radiosondes exhibit a very weak anticorrelation with SABER.

h. No significant correlation is observed between radiosondes and AIRS.

i. SABER and HIRDLS exhibit excellent correlations at all altitudes, consistent with their very similar designs and observational techniques. No significant bias in monthly-median GWPE is observed towards either instrument.

j. SABER shows a very weak correlation with AIRS at the $40 \mathrm{~km}$ level, and no significant correlation below this.

k. No significant correlation is observed between MLSAura and the radiosonde data.

1. MLS-Aura appears very weakly anticorrelated with AIRS at $25 \mathrm{~km}$ and weakly correlated with AIRS at $40 \mathrm{~km}$. 

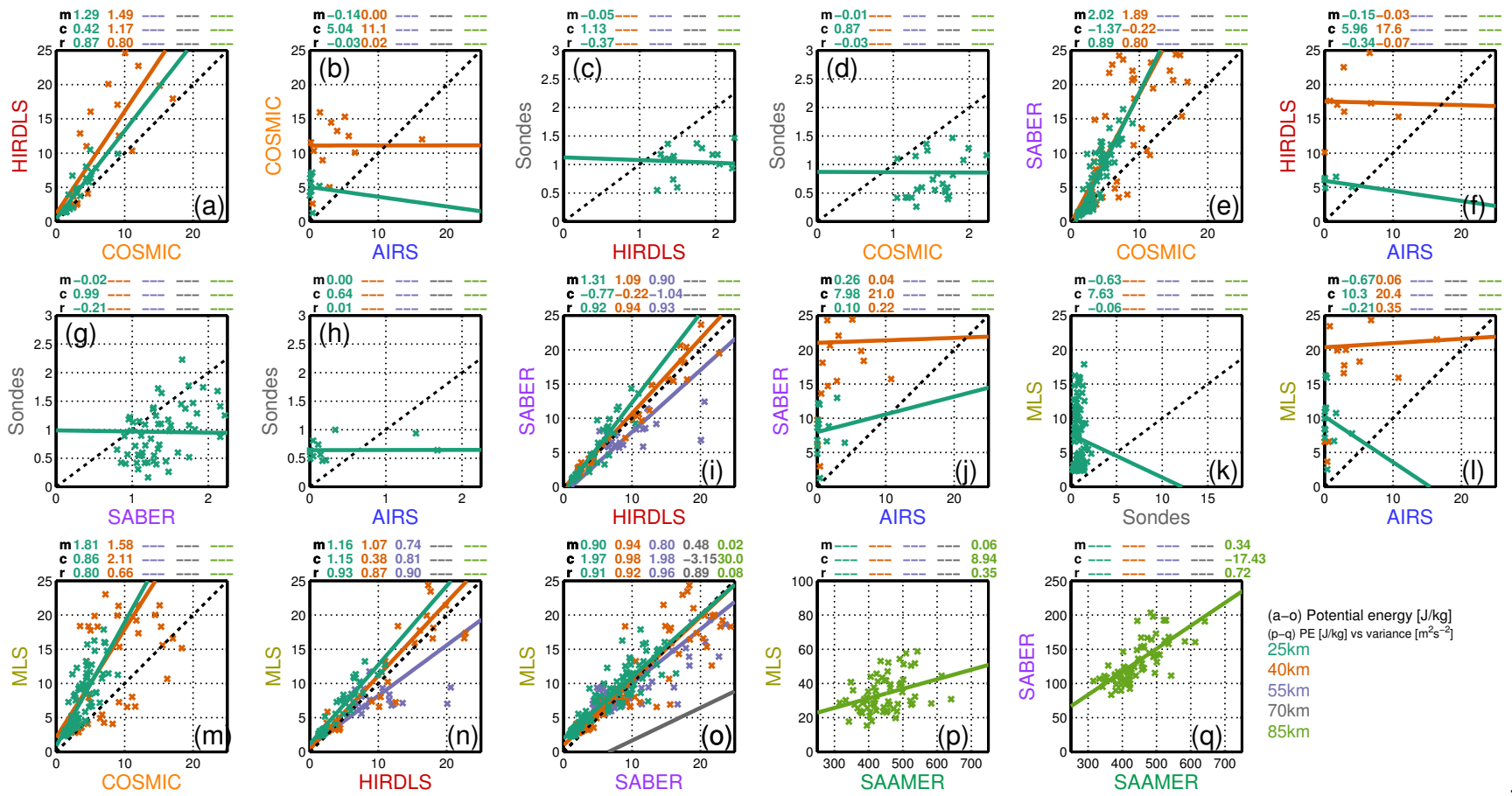

Figure 16. Scatter plots showing the agreement level between the monthly median GWPE measured by each pair of data sets. Data set pairs which do not overlap in altitude have been omitted. For panels (a-c, e-g), the horizontal and vertical axes indicate the GWPE measured by each instrument at all overlapping height levels; the colour indicates the height level considered. The $1: 1$ line of perfect agreement is indicated by the black dotted line, whilst linear fits to the data at each height level are shown by the appropriately coloured line. Gradients $[m]$ and Pearson correlation coefficients $[r]$ for each level are indicated above the corresponding panel. Panel (d) uses the same format, but values shown are normalised to the distribution mean for each instrument due to the different physical quantities under consideration.

m. MLS-Aura and COSMIC show an excellent correlation at the $25 \mathrm{~km}$ level and a good correlation at $50 \mathrm{~km}$. Consistent with other limb-sounder pairings, COSMIC measurements appear low-biased.

n. MLS-Aura and HIRDLS correlate excellently at all altitudes, with no significant bias in fit.

o. MLS-Aura and SABER show excellent correlations at all heights below $85 \mathrm{~km}$. No significant bias is seen at heights up to $55 \mathrm{~km}$, but fits diverge strongly above this height.

p. MLS-Aura and SAAMER show a weak positive correlation.

q. SABER and SAAMER show excellent correlation.

\section{Vertical wavelengths}

We now move on from GWPE to consider the vertical wavelengths of observed gravity waves. Of the instruments and methods under consideration, only five (COSMIC, HIRDLS, MLS-Aura, SABER and the radiosondes) return useful information on this variable, and consequently we consider only these data.
We consider first-time series of the median vertical wavelength at each height level, before considering the observed histograms and, finally, their dependence on wind speeds locally and at the surface.

\subsection{Annual cycle}

Figure 17 shows, for each of the five vertical-wavelengthresolving instruments, the annual cycle of observed $\lambda_{z}$. As with Fig. 12, each panel represents a given instrument at a specific height level. The black dashed line indicates the all-years median, individual coloured lines show the daily median, and box-and-whisker plots show variability within each month over all years. The primary vertical axis on each panel is the base-10 logarithm of the vertical wavenumber measured. This distributes the observations fairly uniformly to allow relatively simple interpretation, but the majority of the discussion below will be in terms of vertical wavelength, shown on the right-vertical axis of each panel. Note that the wavelength/wavenumber range shown is different for each instrument. 

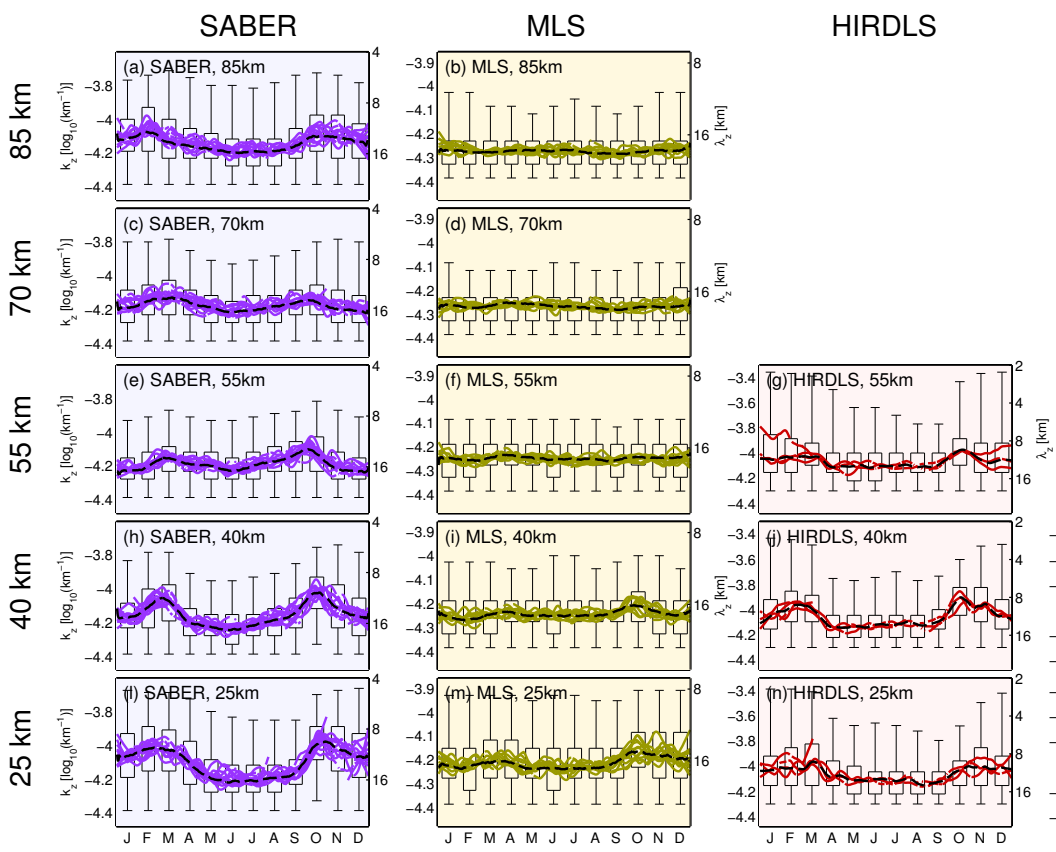

COSMIC

Sondes

Figure 17. As Fig. 12, showing interannual variability of the each observed $\lambda_{z}$ distribution.

We firstly note that each of the limb sounders, with the exception of a single month of SABER data at $25 \mathrm{~km}$ altitude, exhibits a hard cut-off at long vertical wavelengths. This is due to our analytical choices for the S-transform analysis rather than geophysical effects, and suggests that all the distributions studied may extend beyond this limit in the full data sets to some degree. The sondes also exhibit a hard edge at $\lambda_{z} \sim 3 \mathrm{~km}$, for the same reasons. Aside from this feature, all the data sets exhibit clear seasonal cycles.

Variability in the radiosonde monthly median vertical wavelength observations is very small, with variability of only a few percent in the all-years median over the annual cycle. The box-and-whisker plots perhaps suggest a slight shortening of vertical wavelengths around the same time as the GWPE maximum of this data set in April, and also around the latter third of the year, but these effects are small.

Excluding the sondes, HIRDLS at $55 \mathrm{~km}$ and MLS-Aura at high altitudes, all instruments to some degree exhibit an approximately semi-annual cycle, with the shortest median vertical wavelengths in February/March and October. HIRDLS at $55 \mathrm{~km}$ also shows this pattern if the first 3 months of 2008, at the very end of the instrument record, are excluded (not shown); this exclusion is valid, since HIRDLS during this period was suffering from severe technical issues due to erratic behaviour of the optical chopper, an issue which ultimately led to final instrument failure (Gille et al., 2013). The composite-monthly distributions show the same pattern, with the short-wavelength 95th percentile of the distributions (top whisker) reaching values $2-3 \mathrm{~km}$ shorter in these months than in JJA in SABER observations and a similar fractional drop in the other instruments.

This cycle is strongest at low altitudes and weakens with height. These wavelength minima coincide temporally with the lowest absolute wind speeds (Fig. 4). Furthermore, the longest median vertical wavelengths are seen in DecemberJanuary and June-August, again corresponding to high absolute wind speeds. This suggests a strong relationship between wind speed and vertical wavelength for these instruments.

\subsubsection{Wind dependence of $\lambda z$}

Figure 18 examines the relationship between wind speed and vertical wavelength further. As with Fig. 14, each column represents an individual instrument, with the upper panel showing the scatter of observed monthly-median vertical wavelength against the local wind speed, the lower panel against surface wind speed, and different colours indicating different height levels under consideration. The horizontal scale on the upper panels shows vertical wavelength and the horizontal scale on the lower panels shows vertical wavenumber. These two scales correspond, as with the vertical scales in Fig. 17. Vertical wavelength values are quantised to the levels outputted by our S-transform analyses.

As with GWPE, we see very strong correlations for COSMIC, HIRDLS, and SABER between local wind speed and observed vertical wavelength (except for SABER at $85 \mathrm{~km}$ ); correlation coefficients reach values as low as -0.84 (as a negative correlation in wavenumber, equivalent to positive correlation in wavelength) for COSMIC data at $40 \mathrm{~km}$ altitude. While not quite as large in magnitude as the GWPE 

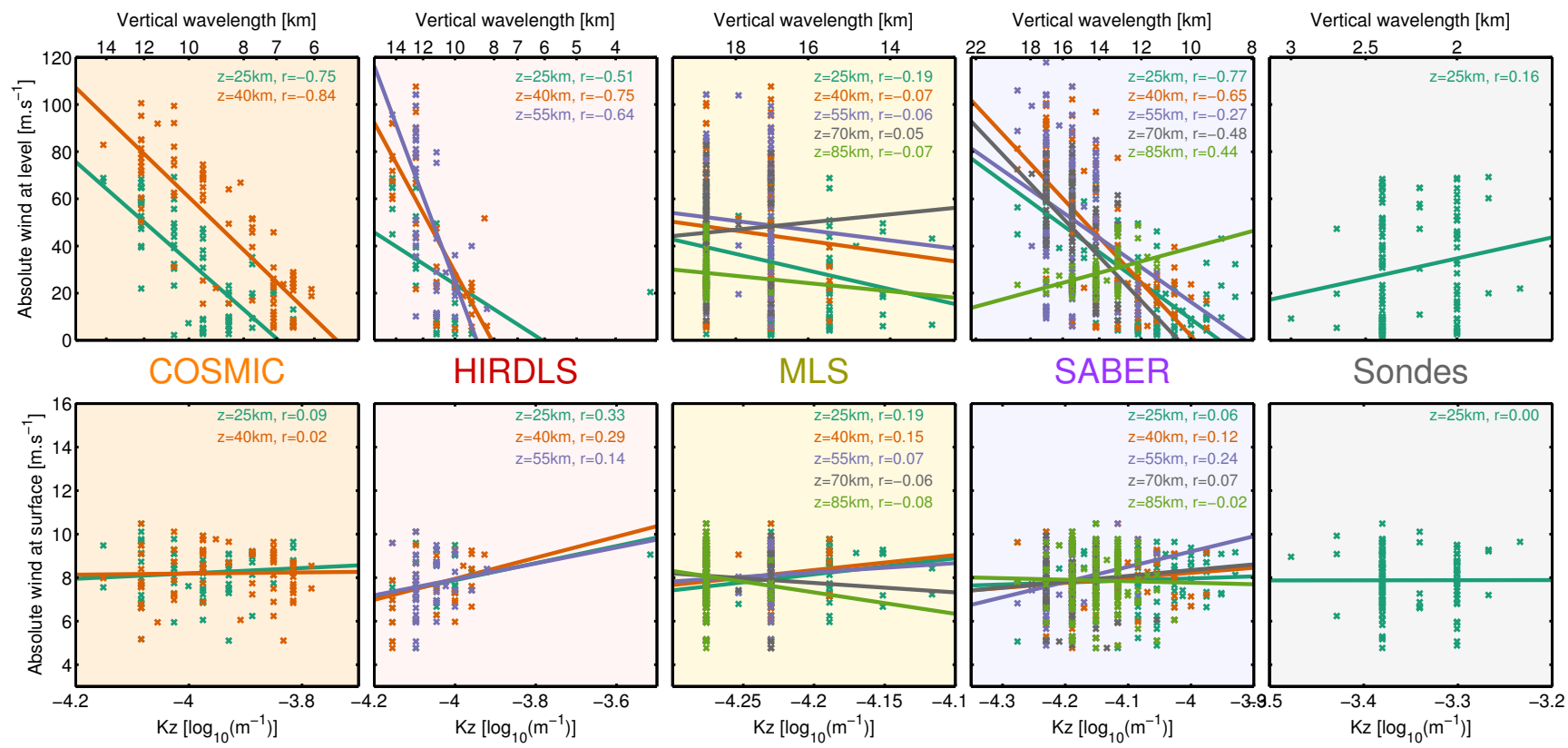

Figure 18. Scatter plots of observed vertical wavenumber against absolute wind speed for each height level (top row) Same data against surface absolute wind speed (bottom row). $[r]$ indicates the Pearson correlation coefficient at each level. Horizontal axes apply to both upper and lower panels.
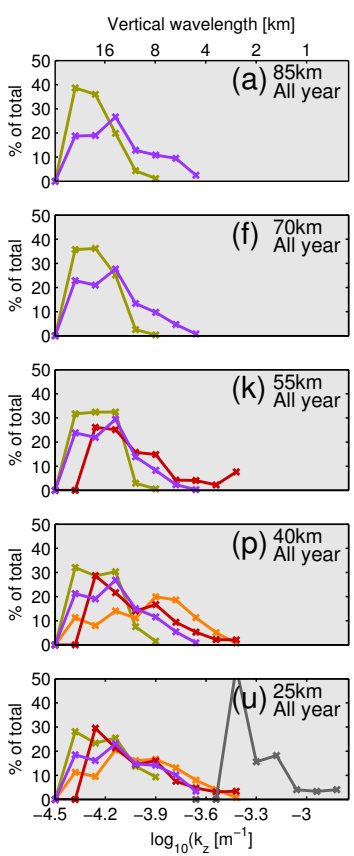
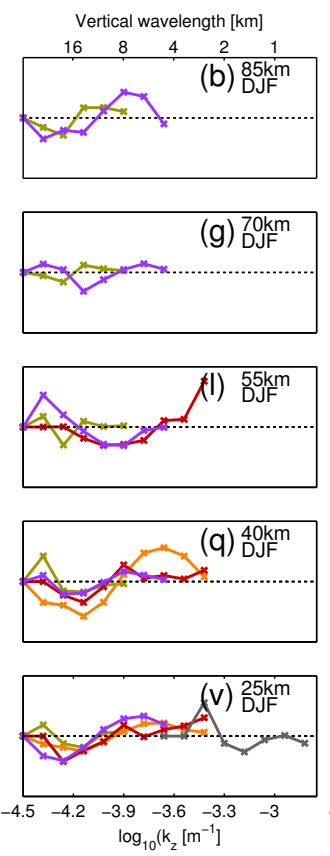
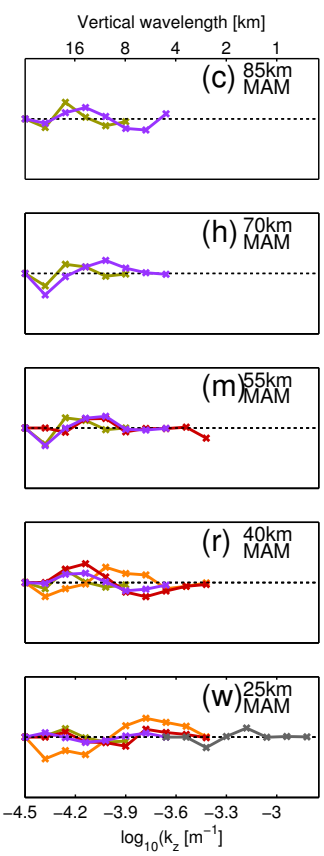
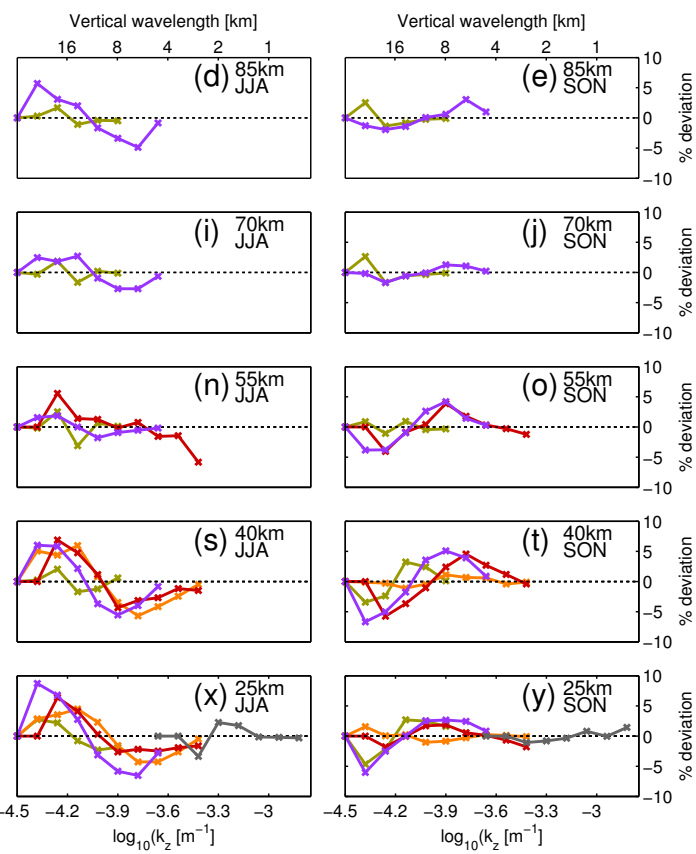

Figure 19. Histograms of observed vertical wavelengths for all limb-sounding instruments at all levels. The leftmost column (a, f, k, p, u) shows histograms of all data considered, normalised to sum to $100 \%$. Remaining panels show differences between the normalised distribution for each season and the annual mean normalised distribution at that high level, as a percentage difference. Top and bottom axes are equivalent. 
correlations examined in Fig. 14, these are still very strong for observations with this type of data. MLS-Aura, however, does not show any such correlation - this may be due to the small range of wavelengths between the observational filter edge and our wavelength cut-off at $30 \mathrm{~km}$. Vertical wavelength is slightly positively correlated with local wind speed in radiosonde measurements, but this is a weak relationship which may just be noise. SABER, interestingly, appears to be fairly robustly positively correlated with wind speed at the $85 \mathrm{~km}$ level, in contrast to the other altitude levels considered.

As with GWPE, instruments do not appear to be significantly correlated with the local surface winds. Of the five data sets, only HIRDLS exhibits any clear trend, and even this is weak at best.

\subsection{Seasonal histograms}

Finally, we consider seasonal histograms of observed vertical wavelength. As with GWPE in Sect. 6.4, we present this as (Fig. 19a, f, k, p, u) all-years histograms and differences from this annual histogram. All data are presented on a common horizontal scale, but appear significantly offset from each other due to differing observational filters and analysis options.

In general, for each instrument the majority of wave observations are towards the longer end of the range of vertical wavelengths observed by that instrument. This is almost certainly methodologically induced to some degree, but use of an overlapping-wave methodology is not expected to significantly change this result in this region (Wright and Gille, 2013, their Fig. 3b) due to the domination of this region by individual large-amplitude waves.

As with Fig. 15, seasonal variations manifest themselves as shifts in the histogram. In general, the annual distribution and seasonal shifts are consistent within the limb sounders, both in form and magnitude. Longer wavelengths are seen in winter and shorter in summer at all heights below the $85 \mathrm{~km}$ level. Sondes exhibit comparatively little variability.

\section{Conclusions}

In this study, we have examined gravity wave potential energy (GWPE) and observed vertical wavelengths of singleprofile measurements obtained from four limb-sounding satellite data sets and one balloon data set, GWPE from a nadir-sounding satellite data set and wind variances from a meteor radar installation. Here, we divide our conclusions into three separate themes, specifically (1) instrumental cross-validation, (2) observational filter effects and (3) geophysical conclusions.

\subsection{Instrument cross-validation}

The spatially co-located analysis of so many data sets provides an excellent opportunity to obtain information about the comparative performance of the different instruments, hence the inclusion of such a wide range of diagnostic figures. This allows us to build substantially upon the work of Wright et al. (2011) in both range of instrumentation considered and altitude range, albeit only in a specific geographic region.

1. We suggest that (single-profile) HIRDLS measurements drop below a useful quality level for S-transform analysis of GWPE and vertical wavelength at heights approaching a $70 \mathrm{~km}$ level. COSMIC experiences a similar limitation at heights above $40 \mathrm{~km}$ levels, at least in this region. HIRDLS performance at around $70 \mathrm{~km}$ altitude may be improved by using covarying profile-pair data (e.g Wright et al., 2015). The poor COSMIC performance appears to be due to anomalously smooth data at these altitudes.

2. MLS-Aura performs surprisingly well at all altitudes given the comparatively limited use of this data set for gravity-wave analysis to date. Since MLS-Aura combines the altitudinal range of SABER with near-global geographic coverage throughout the year, albeit at a much-reduced resolution, this highlights the potential of this data set for future studies. MLS-measured GWPE exhibits a high (low) bias relative to other instruments at low (high) altitudes, most likely due to the observational filter relative to the other limb sounders. The seasonal form of observations remains consistent with the other data sets at these levels, even when magnitudes differ.

3. Meteor radar wind variances (broadly analogous to GWKE) from SAAMER appear to reproduce the seasonal pattern of GWPE in other instruments well, despite a very different observational filter. Given the extremely limited range of cross-validation data sets available at these altitudes, this is useful information, and should be investigated for other meteor radar locations.

4. Limb sounders correlate excellently with each other, and may be substitutable for each other in determining the broad-scale temporal variability of the wave field, at least at the monthly level. In particular, at the 25, 40 and $55 \mathrm{~km}$ altitude levels, no limb-sounder pair exhibits a correlation of less than $0.80,0.66$, and 0.90 respectively in monthly-median GWPE. In the lower two heights, MLS-Aura is significantly less capable than the other three limb sounders, and excluding this from the set increases the minimum correlation to $0.87(0.80)$ at $25 \mathrm{~km}$ $(40 \mathrm{~km})$. 
5. The limb sounders, when analysed using the same method (and, implicitly, focusing on waves of the same vertical scale via the underlying choice to take the largest-amplitude feature at each height), give broadly similar numerical results, suggesting that the large discrepancies in magnitude seen in other studies (e.g. Table 1) are primarily methodological in origin. This highlights that consistent methods should be used when examining such data sets.

\subsection{Observational filter effects}

Our results show clear influences from the observational filters of the different data sets. These differences are important, and will be investigated in greater depth in Part 2. Here we note two conclusions that can be drawn directly from the analyses presented here.

1. Our results reinforce the well-known point that the different observational filters of different data sets lead to different observations of GWPE, in both seasonal form and in magnitude.

2. In particular, the spectral region represented by the radiosonde data set appears to be weakly anticorrelated with that examined by all other height-overlapping data sets, and peaks at quite different times of the year. It thus cannot easily be substituted for other data sets as an overall proxy for wave activity.

\subsection{Geophysics}

The wide range of complementary data sets examined here offers a unique opportunity to examine the wave geophysics of this region. Again, we identify key conclusions that can be drawn from these observations. We will carry out further investigations in Part 2.

1. Evidence of wave dissipation is seen, and varies strongly with season. In particular, there is strong wave dissipation in the mid-stratosphere in summer and in the upper stratosphere in spring. The great majority of this dissipation is consistent with zonal-wind filtering of orographic waves.

2. GWPE observations are distributed log-normally in magnitude. This is similar to the behaviour previously observed for GWMF by Hertzog et al. (2012) and Wright et al. (2013).

3. The temporal variability of observed GWPE in every instrument except SAAMER is dominated by short timescales. For more than half the year in every nonSAAMER data set at every height level, the intramonthly variability is greater than the complete annual variability of the data set median, even after excluding the $0-5$ th and 95-100th percentiles of the distribution.
4. While short-timescale variability is very important, interannual variability at the monthly-median level is relatively small, perhaps with the exception of AIRS and the radiosondes. For the limb sounders, interannual variability in any month is typically less than $\sim 100 \%$ of the monthly median at low altitudes, falling to less than $\sim 30 \%$ at high altitudes. These values may seem initially high, but should be compared to short-timescale variability of many times this magnitude.

5. The observed temporal variability of both GWPE and $\lambda_{z}$ exhibits very little, if any, correlation with surface winds within the region. This is expected, and is consistent with the North American radiosonde observations of Wang and Geller (2003). This does not indicate that the waves observed are not generated or driven by surface or (comparatively) low-altitude processes. Our chosen region lies between the major orographic sources of the Andes and the Antarctic Peninsula, near the southern polar jet edge, and in the range of Southern Ocean storm tracks. Waves generated by any of these sources, or others, would be expected to propagate horizontally into our analysis region (see e.g. Hindley et al., 2015, for orographic GWPE), and thus our results could be completely uncorrelated with local surface winds even if all the waves had low-altitude sources.

6. Our results do suggest a correlation between GWPE and local winds, i.e. those at the same stratospheric/mesospheric level as the gravity-wave observation. This may be due to Doppler shifting of waves into the observational filters of the instruments by these winds.

7. We see an anticorrelation between $k_{z}$ and local winds, i.e. a positive correlation with $\lambda_{z}$. This is again consistent with Doppler shifting effects.

Author contributions. C. J. Wright devised the original concept of the study, performed the AIRS, COSMIC, HIRDLS, MLS-Aura and SABER gravity-wave analyses, produced the figures and interinstrument analyses, and wrote the majority of the text. N. P. Hindley assisted with the analysis and interpretation of the AIRS and COSMIC data. A. C. Moss carried out the gravity-wave analyses for SAAMER. N. J. Mitchell provided the SAAMER data and resources necessary for the other analyses. All authors contributed to the interpretation of the results and the final text.

Acknowledgements. C. J. Wright and N. J. Mitchell are supported by NERC grant NE/K015117/1. N. P. Hindley and A. C. Moss are supported by NERC PhD studentships awarded to the University of Bath. The authors would particularly like to acknowledge the many years of work carried out by all the instrument teams referenced and studied in this article. C. J. Wright would further like 
to acknowledge Tracy Moffat-Griffin (BAS) for useful discussions related to the radiosonde analysis, Scott Osprey (Oxford) for useful discussions relating to wave physics, and the NERC SG-WEX project group for useful discussions related to a very preliminary version of these results.

ECMWF analyses and radiosonde data were obtained from the BADC, COSMIC from the CDAAC, SABER from the GATS, Inc. website, AIRS and MLS-Aura from NASA-Mirador, HIRDLS by direct correspondence with John Gille (NCAR/CU Boulder), and SAAMER by direct correspondence with Diego Janches (NASA GSFC).

Edited by: A. Stoffelen

\section{References}

Alexander, M. J.: Interpretations of observed climatological patterns in stratospheric gravity wave variance, J. Geophys. Res.Atmos., 103, 8627-8640, 1998.

Alexander, M. J. and Barnet, C.: Using Satellite Observations to Constrain Parameterizations of Gravity Wave Effects for Global Models, J. Atmos. Sci., 64, 1652-1665, doi:10.1175/JAS3897.1, 2007.

Alexander, M. J. and Grimsdell, A. W.: Seasonal cycle of orographic gravity wave occurrence above small islands in the Southern Hemisphere: Implications for effects on the general circulation, J. Geophys. Res.-Atmos., 118, 11589-11599, doi:10.1002/2013JD020526, 2013.

Alexander, M. J., Gille, J. C., Cavanaugh, C., Coffey, M., Craig, C., Eden, T., Francis, G., Halvorson, C., Hannigan, J., Khosravi, R., Kinnison, D., Lee, H., Massie, S., Nardi, B., Barnett, J., Hepplewhite, C., Lambert, A., and Dean, V.: Global estimates of gravity wave momentum flux from High Resolution Dynamics Limb Sounder observations, J. Geophys. Res., 113, D15S18, doi:10.1029/2007JD008807, 2008a.

Alexander, M. J., Eckermann, S. D., Broutman, D., and Ma, J.: Momentum flux estimates for South Georgia Island mountain waves in the stratosphere observed via satellite, Geophys. Res. Lett., 36, L12816, doi:10.1029/2009GL038587, 2009a.

Alexander, M. J., Geller, M. A., McLandress, C., Polavarapu, S., Preusse, P., Sassi, F., Sato, K., Eckermann, S. D., Ern, M., Hertzog, A., Kawatani, Y., Pulido, M., Shaw, T. A., Sigmond, M., Vincent, R. A., and Watanabe, S.: Recent developments in gravity-wave effects in climate models and the global distribution of gravity-wave momentum flux from observations and models, Q. J. Roy. Meteor. Soc., 136, 1103-1124, doi:10.1002/qj.637, 2010.

Alexander, P., Luna, D., de la Torre, A., and Schmidt, T.: Distribution functions and statistical parameters that may be used to characterize limb sounders gravity wave climatologies in the stratosphere, Adv. Space Res., 56, 619-633, doi:10.1016/j.asr.2015.05.007, 2015.

Alexander, S. P., Tsuda, T., and Kawatani, Y.: COSMIC GPS Observations of Northern Hemisphere winter stratospheric gravity waves and comparisons with an atmospheric general circulation model, Geophys. Res. Lett., 35, L10808, doi:10.1029/2008GL033174, 2008b.
Alexander, S. P., Klekociuk, A. R., and Tsuda, T.: Gravity wave and orographic wave activity observed around the Antarctic and Arctic stratospheric vortices by the COSMIC GPSRO satellite constellation, J. Geophys. Res.-Atmos., 114, 1-17, doi:10.1029/2009JD011851, 2009b.

Anthes, R. A., Bernhardt, P. A., Chen, Y., Cucurull, L., Dymond, K. F., Ector, D., Healy, S. B., Ho, S. P., Hunt, D. C., Kuo, Y. H., Liu, H., Manning, K., McCormick, C., Meehan, T. K., Randel, W. J., Rocken, C., Schreiner, W. S., Sokolovskiy, S. V., Syndergaard, S., Thompson, D. C., Trenberth, K. E., Wee, T. K., Yen, N. L., and Zeng, Z.: The COSMIC/Formosat-3 mission: Early results, B. Am. Meteorol. Soc., 89, 313-333, doi:10.1175/BAMS89-3-313, 2008.

Aumann, H. H., Chahine, M. T., Gautier, C., Goldberg, M. D., Kalnay, E., McMillin, L. M., Revercomb, H., Rosenkranz, P. W., Smith, W. L., Staelin, D. H., Strow, L. L., and Susskind, J.: AIRS/AMSU/HSB on the Aqua mission: design, science objectives, data products, and processing systems, IEEE Geosci. Remote S., 41, 253-264, doi:10.1109/TGRS.2002.808356, 2003.

Balsley, B. B. and Garello, R.: The kinetic energy density in the troposphere, stratosphere and mesosphere: A preliminary study using the Poker Flat MST radar in Alaska, Radio Sci., 20, 13551361, doi:10.1029/RS020i006p01355, 1985.

Barnett, J. J., Hepplewhite, C. L., Osprey, S., Gille, J. C., and Khosravi, R.: Cross-validation of HIRDLS and COSMIC radiooccultation retrievals, particularly in relation to fine vertical structure, Proceedings of SPIE, 7082, 708216-708216-7, doi:10.1117/12.800702, 2008.

Baumgaertner, A. J. G. and McDonald, A. J.: A gravity wave climatology for Antarctica compiled from Challenging Minisatellite Payload/Global Positioning System (CHAMP/GPS) radio occultations, J. Geophys. Res. Atmos., 112, D05103, doi:10.1029/2006JD007504, 2007.

Beldon, C. L. and Mitchell, N. J.: Gravity waves in the mesopause region observed by meteor radar, 2: Climatologies of gravity waves in the Antarctic and Arctic, J. Atmos. Sol.-Terr. Phy., 71, 875-884, doi:10.1016/j.jastp.2009.03.009, 2009.

Davies, R. N., Wright, C. J., Howells, V. S. C., Janches, D., and Mitchell, N. J.: Gravity-Wave Momentum Fluxes in the MLT region over the Southern Andes and Antarctic Peninsula, Atmos. Chem. Phys. Discuss., in preparation, 2015.

Dowdy, A. J., Vincent, R. a., Tsutsumi, M., Igarashi, K., Murayama, Y., Singer, W., and Murphy, D. J.: Polar mesosphere and lower thermosphere dynamics: 1. Mean wind and gravity wave climatologies, J. Geophys. Res., 112, D17104, doi:10.1029/2006JD008126, 2007.

Eckermann, S. D. and Wu, D. L.: Satellite detection of orographic gravity-wave activity in the winter subtropical stratosphere over Australia and Africa, Geophys. Res. Lett., 39, L21807, doi:10.1029/2012GL053791, 2012.

ECMWF: Assimilated Data from the European Centre for Medium-Range Weather Forecasts (ECMWF) operational analysis program, avialable at: http://catalogue.ceda.ac.uk/uuid/ c46248046f6ce34fc7660a36d9b10a71 (last access: 26 February 2016), 2015.

Ern, M. and Preusse, P.: Gravity wave momentum flux spectra observed from satellite in the summertime subtropics: Implications for global modeling, Geophys. Res. Lett., 39, L15810, doi:10.1029/2012GL052659, 2012. 
Ern, M., Preusse, P., Alexander, M. J., and Warner, C. D.: Absolute values of gravity wave momentum flux derived from satellite data, J. Geophys. Res. Atmos., 109, D20103, doi:10.1029/2004JD004752, 2004.

Ern, M., Preusse, P., Gille, J. C., Hepplewhite, C. L., Mlynczak, M. G., Russell III, J. M., and Riese, M.: Implications for atmospheric dynamics derived from global observations of gravity wave momentum flux in stratosphere and mesosphere, J. Geophys. Res., 116, D19107, doi:10.1029/2011JD015821, 2011.

Ern, M., Ploeger, F., Preusse, P., Gille, J. C., Gray, L. J., Kalisch, S., Mlynczak, M. G., Russell III, J. M., and Riese, M.: Interaction of gravity waves with the QBO: A satellite perspective, J. Geophys. Res.-Atmos., 119, 2329-2355, doi:10.1002/2013JD020731, 2014.

Faber, A., Llamedo, P., Schmidt, T., de la Torre, A., and Wickert, J.: On the determination of gravity wave momentum flux from GPS radio occultation data, Atmos. Meas. Tech., 6, 3169-3180, doi:10.5194/amt-6-3169-2013, 2013.

France, J. A., Harvey, V. L., Alexander, M. J., Randall, C. E., and Gille, J. C.: High Resolution Dynamics Limb Sounder observations of the gravity wave-driven elevated stratopause in 2006, J. Geophys. Res.-Atmos., 117, 1-9, doi:10.1029/2012JD017958, 2012.

Fritts, D. C. and Alexander, M. J.: Gravity Wave Dynamics and Effects in the Middle Atmosphere, Rev. Geophys., 41, 1-64, doi:10.1029/2001RG000106, 2003.

Fritts, D. C., Janches, D., and Hocking, W. K.: Southern Argentina agile meteor radar: Initial assessment of gravity wave momentum fluxes, J. Geophys. Res.-Atmos., 115, D19123, doi:10.1029/2010JD013891, 2010.

Geller, M. A. and J. Gong: Gravity wave kinetic, potential, and vertical fluctuation energies as indicators of different frequency gravity waves, J. Geophys. Res. Atmos., 115, 1-8, doi:10.1029/2009JD012266, 2010.

Geller, M. A., Alexander, M. J., Love, P. T., Bacmeister, J. T., Ern, M., Hertzog, A., Manzini, E., Preusse, P., Sato, K., Scaife, A. a., and Zhou, T.: A Comparison between Gravity Wave Momentum Fluxes in Observations and Climate Models, J. Climate, 26, 6383-6405, doi:10.1175/JCLI-D-12-00545.1, 2013.

Gille, J., Barnett, J., Whitney, J., Dials, M., Woodard, D., Rudolf, W., Lambert, A., and Mankin, W.: The High Resolution Dynamics Limb Sounder (HIRDLS) Experiment on Aura, 5152, 162 171,2003

Gille, J. C., Barnett, J. J., Arter, P., Barker, M., Bernath, P., Boone, C., Cavanaugh, C., Chow, J., Coffey, M., Craft, J., Craig, C., Dials, M., Dean, V., Eden, T., Edwards, D. P., Francis, G., Halvorson, C., Harvey, L., Hepplewhite, C., Khosravi, R., Kinnison, D., Krinsky, C., Lambert, A., Lee, H., Lyjak, L., Loh, J., Mankin, W., Massie, S., McInerney, J., Moorhouse, J., Nardi, B., Packman, D., Randall, C., Reburn, J., Rudolf, W., Schwartz, M., Serafin, J., Stone, K., Torpy, B., Walker, K., Waterfall, A., Watkins, R., Whitney, J., Woodard, D., and Young, G.: High Resolution Dynamics Limb Sounder: Experiment overview, recovery, and validation of initial temperature data, J. Geophys. Res.-Atmos., 113, D16S43, doi:10.1029/2007JD008824, 2008.

Gille, J. C., Gray, L. J., Cavanaugh, C. C., Coffey, M. T., Dean, V., Halvorson, C. M., Karol, S., Khosravi, R., Kinnison, D. E., Massie, S. T., Nardi, B., Belmonte Rivas, M., Smith, L., Torpy, B., Waterfall, A., and Wright, C. J.: High Resolution Dynam- ics Limb Sounder Earth Observing System Data Description and Quality, Version 7, Tech. rep., 2013.

Gong, J., Wu, D. L., and Eckermann, S. D.: Gravity wave variances and propagation derived from AIRS radiances, Atmos. Chem. Phys., 12, 1701-1720, doi:10.5194/acp-12-1701-2012, 2012.

Gong, J., Yue, J., and Wu, D. L.: Global survey of concentric gravity waves in AIRS images and ECMWF analyses, J. Geophys. Res.Atmos., 120, 2210-2228, doi:10.1002/2014JD022527, 2015.

Guest, F. M., Reeder, M. J., Marks, C. J., and Karoly, D. J.: Inertiagravity waves observed in the lower stratosphere over Macquarie Island, J. Atmos. Sci., 57, 737-752, doi:10.1175/15200469(2000)057<0737:IGWOIT>2.0.CO;2, 2000.

Händel, P.: Properties of the IEEE-STD-1057 four-parameter sine wave fit algorithm, IEEE T. Instrum. Meas., 49, 1189-1193, doi:10.1109/19.893254, 2000.

Hei, H., Tsuda, T., and Hirooka, T.: Characteristics of atmospheric gravity wave activity in the polar regions revealed by GPS radio occultation data with CHAMP, J. Geophys. Res.-Atmos., 113, D04107, doi:10.1029/2007JD008938, 2008.

Hertzog, A., Boccara, G., Vincent, R. a., Vial, F., and Cocquerez, P.: Estimation of Gravity Wave Momentum Flux and Phase Speeds from Quasi-Lagrangian Stratospheric Balloon Flights. Part II: Results from the Vorcore Campaign in Antarctica, J. Atmos. Sci., 65, 3056-3070, doi:10.1175/2008JAS2710.1, 2008.

Hertzog, A., Alexander, M. J., and Plougonven, R.: On the intermittency of gravity-wave momentum flux in the stratosphere, $\mathrm{J}$ Atmos. Sci., 69, 3056-3070, doi:10.1175/JAS-D-12-09.1, 2012.

Hindley, N. P., Wright, C. J., Smith, N. D., and Mitchell, N. J.: The southern stratospheric gravity wave hot spot: individual waves and their momentum fluxes measured by COSMIC GPS-RO, Atmos. Chem. Phys., 15, 7797-7818, doi:10.5194/acp-15-77972015, 2015.

Hocking, W. K.: A new approach to momentum flux determinations using SKiYMET meteor radars, Ann. Geophys., 23, 2433-2439, doi:10.5194/angeo-23-2433-2005, 2005.

Hoffmann, L. and Alexander, M. J.: Retrieval of stratospheric temperatures from Atmospheric Infrared Sounder radiance measurements for gravity wave studies, J. Geophys. Res.-Atmos., 114, D07105, doi:10.1029/2008JD011241, 2009.

Hoffmann, L., Alexander, M. J., Clerbaux, C., Grimsdell, A. W., Meyer, C. I., Rößler, T., and Tournier, B.: Intercomparison of stratospheric gravity wave observations with AIRS and IASI, Atmos. Meas. Tech., 7, 4517-4537, doi:10.5194/amt-7-4517-2014, 2014.

John, S. R. and Kumar, K. K.: TIMED/SABER observations of global gravity wave climatology and their interannual variability from stratosphere to mesosphere lower thermosphere, Clim. Dynam., 39, 1489-1505, doi:10.1007/s00382-012-1329-9, 2012.

John, S. R. and Kumar, K. K.: A discussion on the methods of extracting gravity wave perturbations from spacebased measurements, Geophys. Res. Lett., 40, 2406-2410, doi:10.1002/grl.50451, 2013.

Khosravi, R., Lambert, A., Lee, H., Gille, J., Barnett, J., Francis, G., Edwards, D., Halvorson, C., Massie, S., Craig, C., Krinsky, C., McInerney, J., Stone, K., Eden, T., Nardi, B., Hepplewhite, C., Mankin, W., and Coffey, M.: Overview and characterization of retrievals of temperature, pressure, and atmospheric constituents from the High Resolution Dynamics Limb 
Sounder (HIRDLS) measurements, J. Geophys. Res.-Atmos., 114, D20304, doi:10.1029/2009JD011937, 2009.

Krebsbach, M. and Preusse, P.: Spectral analysis of gravity wave activity in SABER temperature data, Geophys. Res. Lett., 34, L03814, doi:10.1029/2006GL028040, 2007.

Kursinski, E. R., Hajj, G. A., Schofield, J. T., Linfield, R. P., and Hardy, K. R.: Observing Earth's atmosphere with radio occultation measurements using the Global Positioning System, J. Geophys. Res., 102, 23429-23465, doi:10.1029/97JD01569, 1997.

Livesey, N. J., Read, W. G., Froidevaux, L., Lambert, A., Manney, G. L., Pumphrey, H. C., Santee, M. L., Schwartz, M. J., Wang, S., Cofield, R. E., Cuddy, D. T., Fuller, R. A., Jarnot, R. F., Jiang, J. H., Knosp, B. W., Stek, P. C., Wagner, P. A., and Wu, D. L.: Earth Observing System (EOS) Aura Microwave Limb Sounder (MLS) Data Quality and Description, version 3.3 and 3.4, 2013.

Livesey, N. J., Read, W. G., Wagner, P. A., Froidevaux, L., Lambert, A., Manney, G. L., Millán Valle, L., Pumphrey, H. C., Santee, M. L., Schwartz, M. J., Wang, S., Fuller, R. A., Jarnot, R. F., Knosp, B. W., and Martinez, E.: Earth Observing System (EOS) Aura Microwave Limb Sounder (MLS) Data Quality and Description, version 4.2, 2015.

McDonald, A. J.: Gravity wave occurrence statistics derived from paired COSMIC/FORMOSAT3 observations, J. Geophys. Res.Atmos., 117, D15106, doi:10.1029/2011JD016715, 2012.

McDonald, A. J., Tan, B., and Chu, X.: Role of gravity waves in the spatial and temporal variability of stratospheric temperature measured by COSMIC/FORMOSAT-3 and Rayleigh lidar observations, J. Geophys. Res.-Atmos., 115, D19128, doi:10.1029/2009JD013658, 2010.

Mertens, C. J., Russell, J. M., Mlynczak, M. G., She, C. Y., Schmidlin, F. J., Goldberg, R. a., López-Puertas, M., Wintersteiner, P. P., Picard, R. H., Winick, J. R., and Xu, $\mathrm{X}$.: Kinetic temperature and carbon dioxide from broadband infrared limb emission measurements taken from the TIMED/SABER instrument, Adv. Space Res., 43, 15-27, doi:10.1016/j.asr.2008.04.017, 2009.

Met Office: Met Office High Resolution Radiosonde Data from the Falkland Islands, available at: http://catalogue.ceda.ac.uk/uuid/ c1e2240c353f8edeb98087e90e6d832e (last access: 26 February 2016), 2015.

Moffat-Griffin, T., Jarvis, M. J., Colwell, S. R., Kavanagh, a. J., Manney, G. L., and Daffer, W. H.: Seasonal variations in lower stratospheric gravity wave energy above the Falkland Islands, J. Geophys. Res.-Atmos., 118, 10861-10869, doi:10.1002/jgrd.50859, 2013.

Niranjan Kumar, K., Ramkumar, T. K., and Krishnaiah, M.: Analysis of large-amplitude stratospheric mountain wave event observed from the AIRS and MLS sounders over the western Himalayan region, J. Geophys. Res.-Atmos., 117, D22102, doi:10.1029/2011JD017410, 2012.

Olsen, E. T., Fishbein, E., Granger, S., Lee, S.-Y., Manning, E., Weiler, M., Blaisdell, J., and Susskind, J.: AIRS/AMSU/HSB Version 5 Data Release User Guide, 2007.

Preusse, P., Eckermann, S. D., and Offermann, D.: Comparison of Global Distributions of Zonal-Mean Gravity Wave variance Inferred from Different Satellite Instruments, Geophys. Res. Lett., 27, 3877-3880, 2000.

Preusse, P., Dörnbrack, A., Eckermann, S. D., Riese, M., Schaeler, B., Bacmeister, J. T., Broutman, D., and Grossman, K. U.:
Space-based measurements of stratospheric mountain waves by CRISTA 1. Sensitivity, analysis method, and a case study, J. Geophys. Res., 107, 8178, doi:10.1029/2001JD000699, 2002.

Preusse, P., Eckermann, S. D., and Ern, M.: Transparency of the atmosphere to short horizontal wavelength gravity waves, J. Geophys. Res.-Atmos., 113, D24104, doi:10.1029/2007JD009682, 2008.

Preusse, P., Eckermann, S. D., Ern, M., Oberheide, J., Picard, R. H., Roble, R. G., Riese, M., Russell, J. M., and Mlynczak, M. G.: Global ray tracing simulations of the SABER gravity wave climatology, J. Geophys. Res., 114, D08126, doi:10.1029/2008JD011214, 2009.

Remsberg, E. E., Marshall, B. T., Garcia-Comas, M., Krueger, D., Lingenfelser, G. S., Martin-Torres, J., Mlynczak, M. G., III, J. M. R., Smith, A. K., Zhao, Y., Brown, C., Gordley, L. L., LopezGonzalez, M. J., Lopez-Puertas, M., She, C.-Y., Taylor, M. J., and Thompson, R. E.: Assessment of the quality of the Version 1.07 temperature-versus-pressure profiles of the middle atmosphere from TIMED/SABER, J. Geophys. Res., 113, D17101, doi:10.1029/2008JD010013, 2008.

Sato, K., Tateno, S., Watanabe, S., and Kawatani, Y.: Gravity Wave Characteristics in the Southern Hemisphere Revealed by a High-Resolution Middle-Atmosphere General Circulation Model, J. Atmos. Sci., 69, 1378-1396, doi:10.1175/JAS-D-110101.1, 2012.

Savitzky, A. and Golay, M. J. E.: Smoothing and Differentiation of Data by Simplified Least Squares Procedures, Anal. Chem., 36, 1627-1639, doi:10.1021/ac60214a047, 1964.

Schoeberl, M. R., Douglass, A. R., Hilsenrath, E., Bhartia, P. K., Beer, R., Waters, J. W., Gunson, M. R., Froidevaux, L., Gille, J. C., Barnett, J. J., Levelt, P. F., and DeCola, P.: Overview of the EOS-Aura mission, IEEE Geosci. Remote S., 44, 1066-1072, doi:10.1109/TGRS.2005.861950, 2006.

Schroeder, S., Preusse, P., Ern, M., and Riese, M.: Gravity waves resolved in ECMWF and measured by SABER, Geophys. Res. Lett., 36, L10805, doi:10.1029/2008GL037054, 2009.

Smout, R., Nash, J., Hewison, T., and Smees, M.: Results of the RS92 Acceptance Test performed by the Met Office (UK), 44, 2005.

Stockwell, R. G., Mansinha, L., and Lowe, R.: Localization of the Complex spectrum: The S Transform, IEEE T. Signal Proces., 44, 998-1001, doi:10.1109/78.492555, 1996.

Trinh, Q. T., Kalisch, S., Preusse, P., Chun, H.-Y., Eckermann, S. D., Ern, M., and Riese, M.: A comprehensive observational filter for satellite infrared limb sounding of gravity waves, Atmos. Meas. Tech., 8, 1491-1517, doi:10.5194/amt-8-1491-2015, 2015.

Tsuda, T., Lin, X., Hayashi, H., and Noersomadi: Analysis of vertical wave number spectrum of atmospheric gravity waves in the stratosphere using COSMIC GPS radio occultation data, Atmos. Meas. Tech., 4, 1627-1636, doi:10.5194/amt-4-1627-2011, 2011.

Vincent, R. A. and Allen, S. J.: Gravity-Wave Parameters in the Lower Stratosphere, in: Gravity Wave Processes and their Parameterization in Global Climate Models, edited by: Hamilton, K., Berlin, Germany, 1996.

Šácha, P., Foelsche, U., and Pišoft, P.: Analysis of internal gravity waves with GPS RO density profiles, Atmos. Meas. Tech., 7, 4123-4132, doi:10.5194/amt-7-4123-2014, 2014. 
Wang, L. and Alexander, M. J.: Gravity wave activity during stratospheric sudden warmings in the 2007-2008 Northern Hemisphere winter, J. Geophys. Res.-Atmos., 114, D18108, doi:10.1029/2009JD011867, 2009.

Wang, L. and Geller, M. A.: Morphology of gravity-wave energy as observed from 4 years (1998-2001) of high vertical resolution U.S. radiosonde data, J. Geophys. Res.-Atmos., 108, 4489-4511, doi:10.1029/2002JD002786, 2003.

Waters, J. W., Froidevaux, L., Harwood, R. S., Jarnot, R. F., Pickett, H. M., Read, W. G., Siegel, P. H., Cofield, R. E., Filipiak, M. J., Flower, D., Holden, J. R., Lau, G. K., Livesey, N. J., Manney, G. L., Pumphrey, H. C., Santee, M. L., Wu, D. L., Cuddy, D. T., Lay, R. R., Loo, M. S., Perun, V. S., Schwartz, M. J., Stek, P. C., Thurstans, R. P., Boyles, M. A., Chandra, K. M., Chavez, M. C., Chudasama, B. V., Dodge, R., Fuller, R. A., Girard, M., Jiang, J. H., Knosp, B. W., LaBelle, R. C., Lam, J. C., Lee, K., Miller, D., Oswald, J. E., Patel, N. C., Pukala, D. M., Quintero, O., Scaff, D. M., Van Snyder, W., Tope, M. C., Wagner, P., and Walch, M. J.: The Earth Observing System Microwave Limb Sounder (EOS MLS) on the Aura Satellite, IEEE Geosci. Remote S., 44, 1075-1092, doi:10.1109/TGRS.2006.873771, 2006.

Wrasse, C., Fechine, J., Takahashi, H., Denardini, C., Wickert, J., Mlynczak, M., Russell, J., and Barbosa, C.: Temperature comparison between CHAMP radio occultation and TIMED/SABER measurements in the lower stratosphere, Adv. Space Res., 41, 1423-1428, doi:10.1016/j.asr.2007.06.073, 2008.

Wright, C. J.: Stratospheric Gravity Wave Measurements using HIRDLS Data, "\{DPhil (PhD) Thesis, University of Oxford $\} "$, University of Oxford, http://ora.ouls.ox.ac.uk/objects/uuid: ef4aa65d-67c1-43ac-90de-1b5bda6c8230 (last access: 12 February 2016), 2010.

Wright, C. J. and Gille, J. C.: HIRDLS observations of gravity wave momentum fluxes over the monsoon regions, J. Geophys. Res., 116, D12103, doi:10.1029/2011JD015725, 2011.

Wright, C. J. and Gille, J. C.: Detecting overlapping gravity waves using the S-Transform, Geophys. Res. Lett., 40, 1850-1855, doi:10.1002/grl.50378, 2013.
Wright, C. J., Osprey, S. M., Barnett, J. J., Gray, L. J., and Gille, J. C.: High Resolution Dynamics Limb Sounder measurements of gravity wave activity in the 2006 Arctic stratosphere, J. Geophys. Res.-Atmos., 115, D02105, doi:10.1029/2009JD011858, 2010.

Wright, C. J., Rivas, M. B., and Gille, J. C.: Intercomparisons of HIRDLS, COSMIC and SABER for the detection of stratospheric gravity waves, Atmos. Meas. Tech., 4, 1581-1591, doi:10.5194/amt-4-1581-2011, 2011.

Wright, C. J., Osprey, S. M., and Gille, J. C.: Global observations of gravity wave intermittency and its impact on the observed momentum flux morphology, J. Geophys. Res.-Atmos., 118, 1098010993, doi:10.1002/jgrd.50869, 2013.

Wright, C. J., Osprey, S. M., and Gille, J. C.: Global distributions of overlapping gravity waves in HIRDLS data, Atmos. Chem. Phys., 15, 8459-8477, doi:10.5194/acp-15-8459-2015, 2015.

Wright, C. J., Hindley, N. P., and Mitchell, N. J.: Combining AIRS and MLS Observations for Three-Dimensional Gravity Wave Measurement, Geophys. Res. Lett., 43, 884-893, doi:10.1002/2015GL067233, 2016.

Wu, D. L. and Eckermann, S. D.: Global Gravity Wave Variances from Aura MLS: Characteristics and Interpretation, J. Atmos. Sci., 65, 3695-3718, doi:10.1175/2008JAS2489.1, 2008.

Wu, D. L., Preusse, P., Eckermann, S. D., Jiang, J. H., de La Torre Juarez, M., Coy, L., and Wang, D. Y.: Remote sounding of atmospheric gravity waves with satellite limb and nadir techniques, Adv. Sp. Res., 37, 2269-2277, doi:10.1016/j.asr.2005.07.031, 2006.

Yan, X., Arnold, N., and Remedios, J.: Global observations of gravity waves from High Resolution Dynamics Limb Sounder temperature measurements: A yearlong record of temperature amplitude and vertical wavelength, J. Geophys. Res.-Atmos., 115, D10113, doi:10.1029/2008JD011511, 2010.

Zhang, Y., Xiong, J., Liu, L., and Wan, W.: A global morphology of gravity wave activity in the stratosphere revealed by the 8-year SABER/TIMED data, J. Geophys. Res.-Atmos., 117, D21101, doi:10.1029/2012JD017676, 2012. 